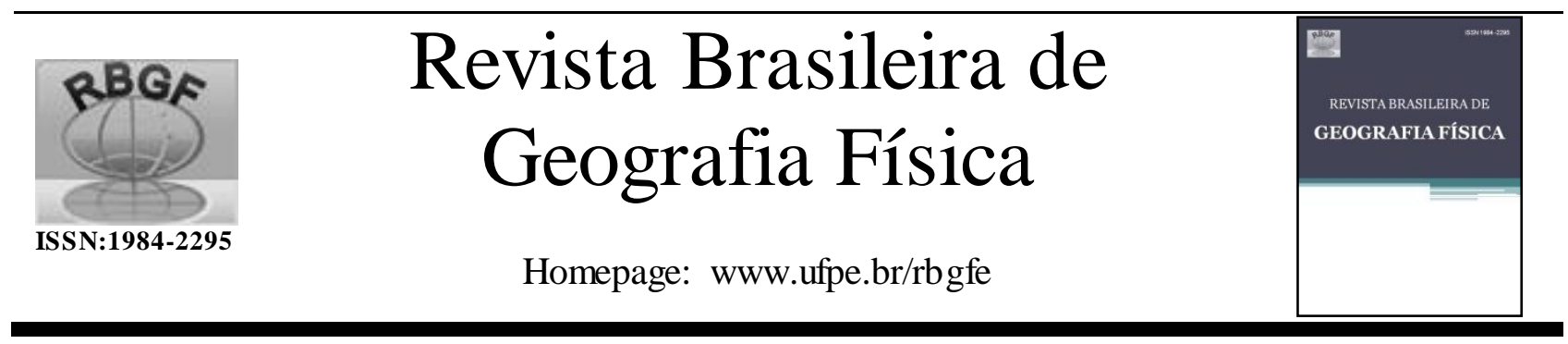

\title{
Perda de Solo e Água e Riscos Ambientais da Concentração de Nutrientes no Escoamento Superficial em Solo Cultivado no Sistema de Plantio Direto e Submetido a Adubações Orgânicas e Mineral ${ }^{1}$
}

\begin{abstract}
Jully Gabriela Retzlaf de Oliveira ${ }^{2}$, Graziela Moraes de Cesare Barbosa ${ }^{3}$, João Tavares Filho ${ }^{4}$, Eloisa Cristiane Torres ${ }^{5}$
${ }^{2}$ Prof ${ }^{a}$. Dra. do Dept ${ }^{\circ}$ de Geografia, Universidade Estadual do Norte do Paraná, UENP, Cornélio Procópio, PR. E-mail: jullygeo@yahoo.com.br (autor correspondente). ${ }^{3}$ Pesquisadora $\mathrm{Dr}^{\mathrm{a}}$. Do Instituto Agronômico do Paraná, IAPAR, Área de Física do Solo, Londrina, PR. E-mail: graziela_barbosa@iapar.br. ${ }^{4}$ Prof. Dr. do Dept ${ }^{\circ}$ de Agronomia, Universidade Estadual de Londrina, UEL, Londrina, PR. E-mail: tavares@uel.br. ${ }^{5}$ Profa. Dra. do Dept ${ }^{\circ}$ de Geografia, Universidade Estadual de Londrina, UEL, Londrina, PR. E-mail: elotorres@uel.br
\end{abstract}

Artigo recebido em 22/07/2015 e aceito em 23/07/2015

\section{RES U M O}

Os resíduos de animais constituem uma excelente fonte de nutrientes, especialmente nitrogênio - $\mathrm{N}$ e fósforo - $\mathrm{P}$, por outro lado, aplicações em quantidades elevadas de dejetos podem extrapolar os benefícios do fertilizante e aumentar os riscos ambientais, implicando em altas cargas de nutrientes, metais e patógenos no ambiente. O objetivo deste trabalho foi avaliar as perdas de água, solo e nutrientes no escoamento superficial e os riscos ambientais advindos destas perdas em Latossolo Vermelho distroférrico cultivado no Sistema de Plantio Direto e submetido a adubações orgânicas com dejeto líquido suíno e cama de aviário e adubação mineral. As avaliações foram realizadas na área experimental do IAPAR em Londrina - PR em um Latossolo Vermelho Distroférrico, submetido ao Sistema de Plantio Direto. Os tratamentos constituíram de Controle (sem adubação); adubação mineral - AM (60 kg N ha-1 através da fórmula 10-30-10); doses de Dejeto Líquido Suíno - DLS: DLS 100 (equivalente a $60 \mathrm{~kg} \mathrm{~N}$ ha-1), DLS 200 (equivalente a $120 \mathrm{~kg} \mathrm{~N}$ ha-1) e doses de Cama de Aviário - CA: CA100 (equivalente a $60 \mathrm{~kg} \mathrm{~N}$ ha-1) e CA 200 (equivalente a $120 \mathrm{~kg} \mathrm{~N}$ ha-1). As avaliações foram realizadas através de chuva simulada em dois períodos (junho/2010 e setembro/2012). As perdas de água, solo e concentrações de NH4+, NO3-, Pdisp., Zn e Cu no escoamento superficial observadas neste estudo constituemuma fonte poluidora para águas superficiais de clas se I, indicando que a aplicação de adubos orgânicos e mineral deve ser monitorada para não caus ar contaminação ambiental e riscos à saúde humana.

Palavras-chave: Dejeto Líquido Suíno, Cama de Aviário, Erosão Hídrica, Poluição Ambiental.

\section{Soil and Water Losses and Environmental Risks of nutrient concentration in surface runoff in Soil Cultivated in No-Till Area and Submitted to Organic and Mineral fertilization}

\begin{abstract}
Animal waste are an excellent source of nutrients, particularly nitrogen $-\mathrm{N}$ and phosphorus - $\mathrm{P}$, on the other hand, applications in high amounts of waste can exceed the benefits of fertilizer and increase environmental hazards, res ulting in high loads of nutrients, pathogens and metals in the environment. The objective of this study was to evaluate the water, soil and nutrients losses in runoff and environmental risks from these losses in a Oxisol cultivated in No-Till System and subjected to organic fertilization with pig slurry and poultry manure and mineral fertilizer. The evaluations were performed in the experimental area of IAPAR in Londrina - PR for a Oxisol, submitted to No-Till System. The treatments were control(without fertilizer); mineral fertilizer - MF (60 kg N ha-1 using the formula 10-30-10); Pig Slurry - PS doses: PS 100 (equivalent to $60 \mathrm{~kg} \mathrm{~N}$ ha-1), PS 200 (equivalent to $120 \mathrm{~kg} \mathrm{~N}$ ha-1) and Poultry Manure - PM doses: PM 100 (equivalent to $60 \mathrm{~kg} \mathrm{~N}$ ha -1) and PM 200 (equivalent to $120 \mathrm{~kg}$ ha-1). The evaluation was performed using simulated rain in two periods (June / 2010 and September / 2012). The water and soil losses, and NH4+, NO3-, available P, Zn and $\mathrm{Cu}$ concentrations in runoff observed in this study are a source of pollution to surface water class I, indicating that the application of organic and mineral fertilizers should be monitored for not cause environmental contamination and risks to human health.
\end{abstract}

Keywords: Pig Slurry; Poultry Manure; Water Erosion; Environmental Pollution.

1 Parte da tese de doutorado da primeira autora. 


\section{Introdução}

O tipo de manejo do solo pode influenciar as taxas de erosão hídrica dependendo da maior ou menor exposição do solo ao impacto das gotas de chuva e a ação da enxurrada. Com essa degradação da estrutura do solo, perdas de solo, água e nutrientes tornam-se frequentes e contribuem para a diminuição da fertilidade química, física e biológica, acarretando sérios danos ao setor agropecuário.

A técnica do plantio direto baseia-se na menor mobilização possíveldo solo em todos os seus aspectos (extensão de superfície do terreno trabalhada, profundidade de preparo e grau de fragmentação do volume de solo mobilizado). Nessa prática, o solo é rompido apenas na linha de semeadura ou plantio de mudas/partes vegetativas das plantas, ficando os resíduos culturais remanescentes de culturas anteriores quase todos na superfície. Apresenta o menor grau de rugosidade superficial e nenhum valor adicional de porosidade total da camada arável, além de resultar em uma superfície de solo geralmente consolidada, condição que, com o tempo, favorece a conservação do solo, mas, em alguns casos, desfavorece a conservação da água (Gilles et. al., 2009).

Pesquisas têm demonstrado a eficácia dos preparos conservacionistas de solo no controle da erosão, com reduções de 50 a $95 \%$ nas perdas de solo, em relação ao preparo convencional. No entanto, as perdas de água, de modo geral, têm sido variadas e bem menos influenciadas pela cobertura superficial morta do que as perdas de solo, podendo ser superiores ora na semeadura direta, ora no preparo reduzido, ora no preparo convencional, ou mesmo semelhantes entre os diferentes métodos de preparo do solo, dependendo de condições, tais como: regime de chuva, tipo de solo, topografia e sequência/rotação cultural (Cogo; Levien e Schwarz, 2003).

A perda de nutrientes por erosão hídrica é afetada pelo método de preparo do solo e pelos seus teores no solo, estes últimos sendo muito dependentes das aplicações de adubos e corretivos e, especialmente, do emprego de métodos de preparo em que há pouco ou nenhum revolvimento de solo (Gilles et al.,2009).

Além do manejo do solo deve-se analisar também o efeito do tipo de adubo utilizado, a forma de aplicação e a dose. $\mathrm{O}$ aumento da produção de suínos e aves no Brasil na última década culminou no aumento do volume de dejeto gerado e consequentemente a utilização de dejetos de animais como fertilizante agrícola aumentou. Neste contexto diversas pesquisas tem avaliado a influência dos métodos de preparo do solo e do tipo de adubação nas perdas de água e solo no escoamento superficial (Bertol et al., 2007; Peles, 2007; Fusco et al., 2009; Gilles et al., 2009; Lemos, 2011) e nas perdas de nutrientes (Ceretta et al., 2005b; Dal Bosco et al., 2008; Mori et al., 2009; Bertol et al., 2010; Silveira et al., 2011; Lourenzi et al., 2014b), enfatizando a aplicação de dejetos de animais em solos cultivados no sistema plantio direto.

Os resíduos de animais constituem uma excelente fonte de nutrientes, especialmente $\mathrm{N}$ e $\mathrm{P}$, e quando manejados adequadamente, podem suprir, parcial ou totalmente, o fertilizante químico na produção de grãos e pastagens (Konzen e Alvarenga, 2005). Por outro lado, aplicações em quantidades elevadas de dejetos podem extrapolar os benefícios do fertilizante e aumentar os riscos ambientais, implicando em altas cargas de nutrientes, metais e patógenos entre outros $(\mathrm{N}, \mathrm{P}, \mathrm{Cu}$ e Zn) no ambiente (Seganfredo, 2000). Esses elementos poderiam ser acumulados em altos níveis comprometendo a qualidade do solo e da água, causando contaminação ambiental e restrição de uso para determinadas finalidades.

O objetivo deste trabalho foi avaliar as perdas de água, solo e nutrientes no escoamento superficial e os riscos ambientais advindos destas perdas em Latossolo Vermelho distroférrico cultivado no Sistema de Plantio Direto e submetido a adubações orgânicas com dejeto líquido suíno e cama de aviário e adubação mineral.

\section{Material e Métodos}

O estudo foi conduzido no Instituto Agronômico do Paraná - IAPAR, localizado em Londrina-PR, sob as coordenadas geográficas $23^{\circ} 21^{\prime} 54^{\prime \prime} \mathrm{S}$ e $51^{\circ} 09^{\prime} 12^{\prime \prime} \mathrm{W}$, altitude média $569 \mathrm{~m}$ (fig. 1), em área submetida ao Sistema de Plantio Direto com rotações de culturas no verão (soja/milho) e inverno (aveia/aveia+nabo+ervilhaca/trigo). 


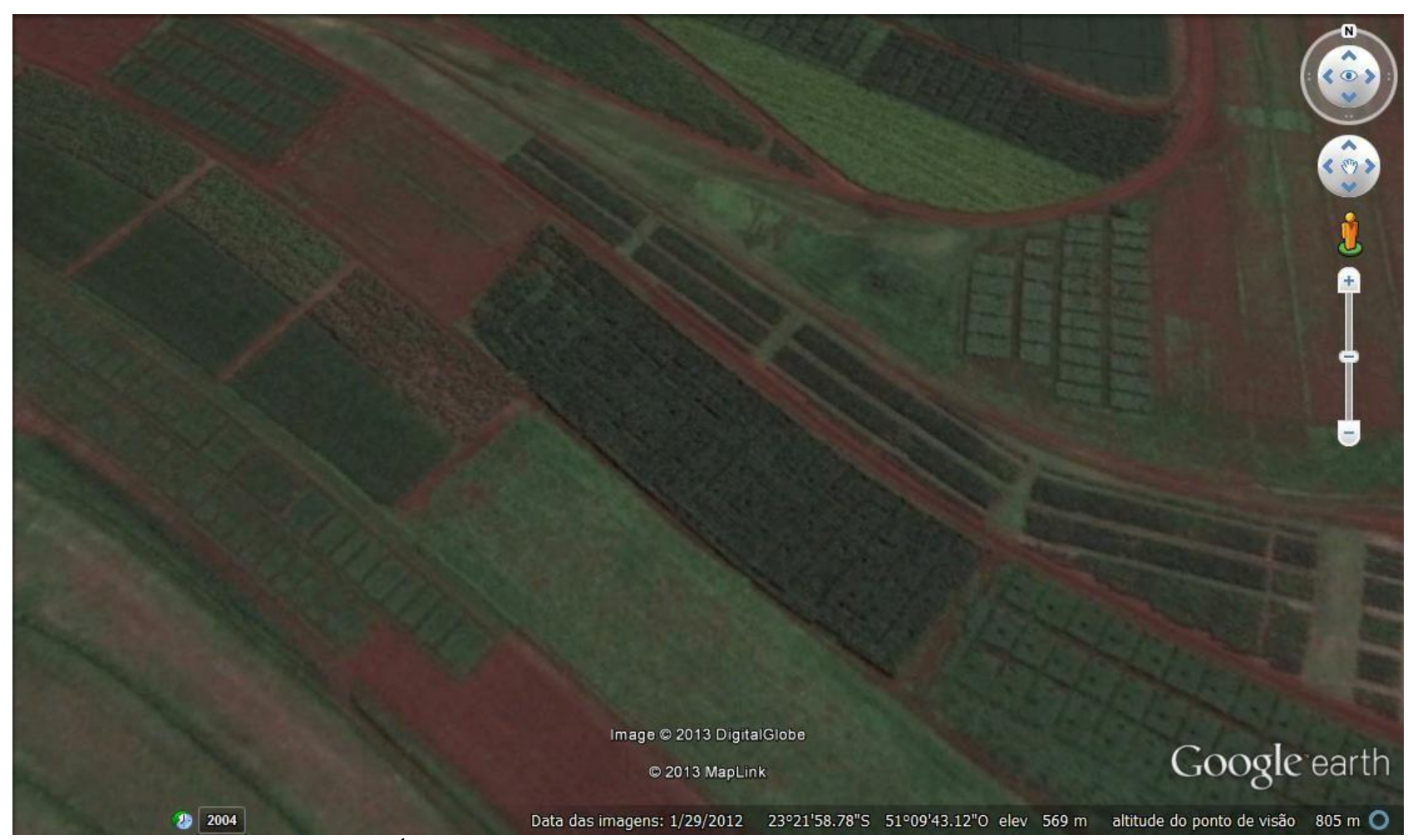

Figura 1. Imagem de Satélite da Área do Experimento. IAPAR, Londrina - Pr.

A área experimental está localizada na bacia hidrográfica do Ribeirão Cafezal (fig. 2). O solo foi classificado como Latossolo Vermelho distroférrico, com os seguintes atributos físicos na implantação do experimento em 2008 (tabela 1). O clima da região na classificação de Koppen é do tipo Cfa, com verões quentes e geadas pouco frequentes, com tendências de concentração das chuvas nos meses de verão, sem estação seca definida. A média das temperaturas dos meses mais quentes é superior a $22^{\circ} \mathrm{C}$, e a dos meses mais frios é inferior a $18^{\circ} \mathrm{C}$, com precipitação média anual de $1200 \mathrm{~mm}$ (Maack, 2002).

Tabela 1 Densidade do solo (Ds) e de partículas (Dp), Porosidade total (PT), macro e microporosidade de um Latossolo Vermelho distroférrico da área experimental.

\begin{tabular}{|cccccc|}
\hline Prof. & Ds & Dp & PT & Micro & Macro \\
\hline m & -------------- g & cm-3--------------- & $---------------c m-3$ & cm-3---------------- \\
\hline $0,0-0,10$ & 1,17 & 2,87 & 0,59 & 0,42 & 0,17 \\
$0,10-0,20$ & 1,20 & 2,88 & 0,58 & 0,42 & 0,16 \\
$0,20-0,30$ & 1,19 & 2,91 & 0,59 & 0,41 & 0,18 \\
$0,30-0,40$ & 1,18 & 2,92 & 0,59 & 0,41 & 0,18 \\
\hline
\end{tabular}




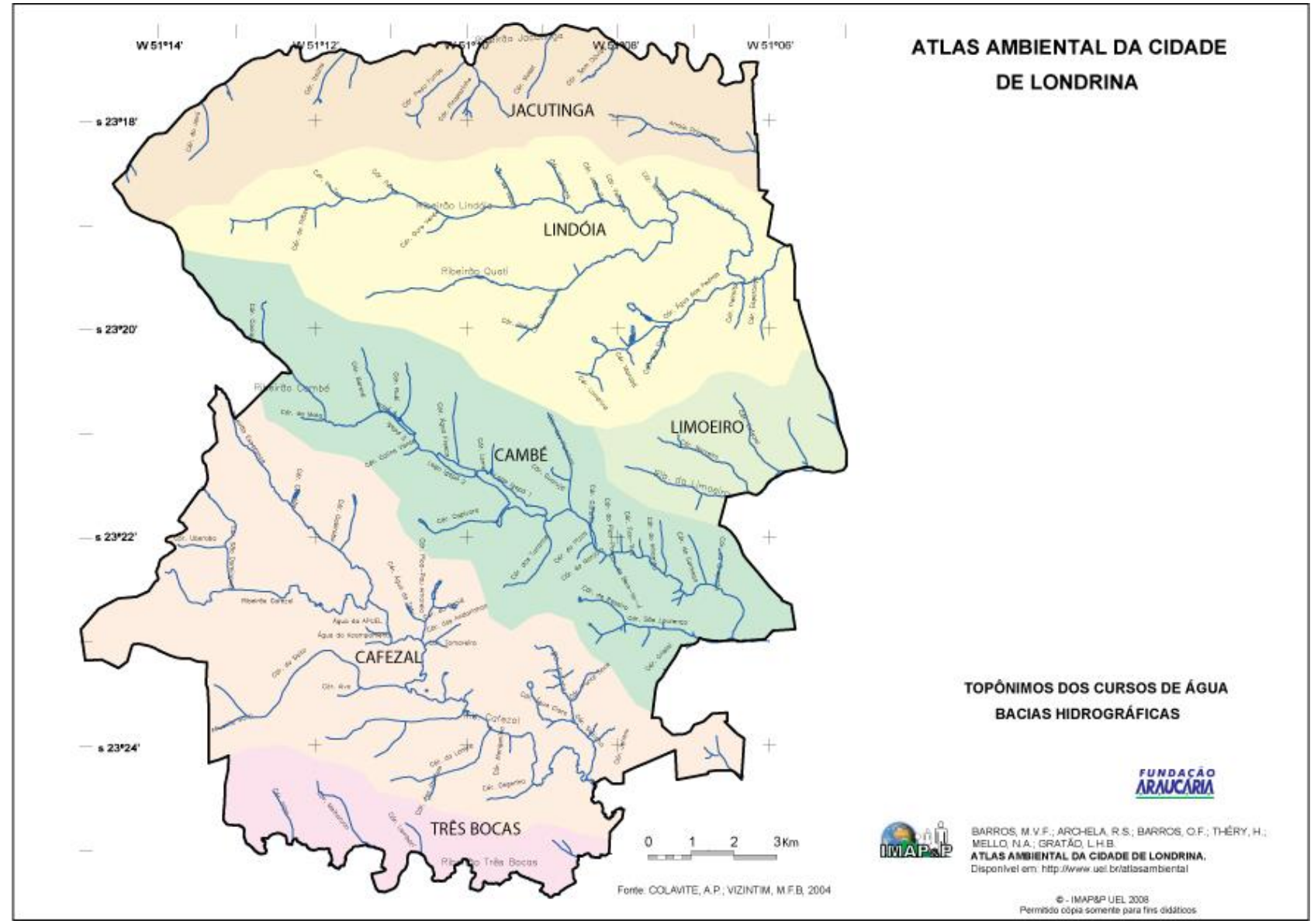

Figura 2. Bacias Hidrográficas de Londrina. Fonte: Atlas Ambiental da Cidade de Londrina, 2008.

Antes deste estudo a referida área estava sendo manejada com experimento de algodão. No início deste experimento, no inverno de 2008, foi plantado aveia, sem adubação nenhuma para esgotar os nutrientes do solo.
Em outubro de 2008 foi feita a divisão do experimento no campo e aplicada as primeiras doses de adubação (dejeto liquido suíno - DLS, Cama de aviário - CA e adubação mineral). A sequencia das culturas implantadas entre 2008 e 2012 estão no quadro abaixo (tabela 2).

Tabela 2 .Sequencia das culturas implantadas entre 2008 e 2012 na área experimental.

\begin{tabular}{|ll|}
\hline Época & Cultura \\
\hline verão/2008 & Soja \\
inverno/2009 & Aveia \\
verão/2009 & Milho \\
inverno/2010 & Trigo \\
verão/2010 & Soja \\
inverno/2011 & Aveia \\
verão/2011 & Milho \\
inverno/2012 & Aveia \\
verão/2012 & Soja \\
\hline
\end{tabular}

O delineamento experimental foi em blocos casualizados com quatro repetições em parcelas de $50 \mathrm{~m} 2(10 \mathrm{~m} \times 5 \mathrm{~m})$. Para cada ensaio foram aplicadas doses de dejeto líquido de suíno (DLS) e cama de aviário (CA) antes do plantio da safra de verão e inverno. As doses do DLS e CA foram calculadas de acordo com a exigência da cultura em nitrogênio ou fósforo. As doses utilizadas foram: Controle (sem adubação); adubação mineral (AM) recomendada com $60 \mathrm{~kg} \mathrm{~N}$ ha-1 através da fórmula 10-30-10; aplicação de $33 \mathrm{~m} 3$ ha-1 de DLS (DLS 100) equivalente a $60 \mathrm{~kg} \mathrm{~N}$ ha-1; aplicação de 66 $\mathrm{m} 3$ ha-1 de DLS (DLS 200) equivalente a $120 \mathrm{~kg} \mathrm{~N}$ ha- 
1; aplicação de $1.920 \mathrm{~kg}$ ha-1 de CA (CA 100) equivalente a $60 \mathrm{~kg} \mathrm{~N}$ ha-1; aplicação de $3.840 \mathrm{~kg}$ ha-1 de CA (CA 200) equivalente a $120 \mathrm{~kg} \mathrm{~N}$ ha-1.

\section{Aplicação do Dejeto líquido Suíno}

O dejeto líquido de suíno (DLS) utilizado foi retirado de lagoa de estabilização, na qual foi homogeneizado antes da coleta, com auxílio de trator e bomba submersa para retirada das frações sólidas e líquidas do resíduo e levado até o experimento em caminhão tanque próprio para transporte de resíduos. Os dejetos foram aplicados manualmente, com o auxílio de regadores, antes da semeadura e em cobertura.

As características do DLS aplicado nas parcelas em 2010 e 2012 encontram-se nas tabelas 3 e 4.

Tabela 3. Teores de nutrientes presentes no dejeto líquido de suíno em junho/2010

\begin{tabular}{|c|c|c|c|c|c|c|c|c|}
\hline $\mathrm{N}$ & $\mathrm{P}$ & $\mathrm{Ca}$ & $\mathrm{Mg}$ & $\mathrm{Mn}$ & $\mathrm{k}$ & $\mathrm{Cu}$ & $\mathrm{Zn}$ & B \\
\hline - & g kg-1- & - & & & ----mg & -1------- & & \\
\hline 9,97 & 519 & 15,26 & 2,77 & 1,46 & 4,17 & 105,32 & 126,2 & 15,91 \\
\hline
\end{tabular}

Tabela 4. Teores de nutrientes presentes no dejeto líquido de suíno em maio/2012

\begin{tabular}{|c|c|c|c|c|c|c|c|c|}
\hline $\mathrm{N}$ & $\mathrm{P}$ & K & $\mathrm{Ca}$ & $\mathrm{Mg}$ & $\mathrm{Cu}$ & $\mathrm{Zn}$ & B & $\mathrm{Mn}$ \\
\hline \multicolumn{6}{|c|}{-------------g kg-1------------ } & --------- & kg-1--- & \\
\hline 38,82 & 18,62 & 22,0 & 22,83 & 9,12 & 962,0 & 2498,0 & 26,04 & 628,70 \\
\hline
\end{tabular}

Aplicação da Cama de Aviário

A cama de frango utilizada foi proveniente da criação intensiva de frangos de corte coletada após a saída de 6 lotes de frango, criados em galpão com substrato de sepilho. Após a obtenção dos dejetos estes foram levados para o experimento e aplicados manualmente a lanço, antes da semeadura e em cobertura.

As características da CA aplicada nas parcelas em 2010 e 2012 encontram-se nas tabelas 5 e 6.

Tabela 5. Teores de nutrientes presentes na cama de aviário em junho/2010

\begin{tabular}{|c|c|c|c|c|c|c|c|c|}
\hline $\mathrm{N}$ total & $\mathrm{P}$ & $\mathrm{Ca}$ & $\mathrm{Mg}$ & $\mathrm{Mn}$ & $\mathrm{k}$ & $\mathrm{Cu}$ & $\mathrm{Zn}$ & B \\
\hline & 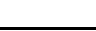 & & & & & & & \\
\hline 25,97 & 40,44 & 47,14 & 9,03 & 1,15 & 21,54 & 102,37 & 1092 & 58,36 \\
\hline
\end{tabular}

Tabela 6. Teores de nutrientes presentes na cama de aviário em maio/2012

\begin{tabular}{|c|c|c|c|c|c|c|c|c|}
\hline $\mathrm{N}$ & $\mathrm{P}$ & $\mathrm{K}$ & $\mathrm{Ca}$ & $\mathrm{Mg}$ & $\mathrm{Cu}$ & $\mathrm{Zn}$ & B & $\mathrm{Mn}$ \\
\hline 14,65 & 13,42 & 28,00 & 40,83 & 10,74 & 81,6 & 411,1 & 47,0 & 757,8 \\
\hline
\end{tabular}

\section{Avaliações sob chuva simulada}

Foram realizadas duas avaliações (a primeira em agosto/2010, e a segunda em setembro/2012) com chuva simulada no experimento. Em ambas foi utilizado um simulador portátil descrito por Roth (1985) de $70 \mathrm{~mm}$ de intensidade durante uma hora. Em cada parcela do experimento foi instalada uma caixa metálica de $50 \times 50$ x $25 \mathrm{~cm}$. Esta caixa foi cravada no solo até $7 \mathrm{~cm}$ de profundidade e a altura restante permitiu a coleta da solução resultante do arraste superficial, por meio de uma calha coletora ligada através de mangueira a um recipiente de armazenamento. A água do escoamento superficial foi coletada por um período contínuo de 60 minutos e o volume total coletado foi enviado para o laboratório para análise.

Na primeira avaliação do escoamento superficial, em 2010, os dejetos foram aplicados em junho, antes do plantio de inverno (trigo IPR 130,) e a aplicação da chuva ocorreu em agosto.

Na segunda avaliação do escoamento superficial, em 2012, os dejetos foram aplicados em maio, antes do plantio de inverno (aveia), e a aplicação da chuva 
ocorreu setembro.

No laboratório foi determinado o volume de água coletada em cada parcela. Após decantação do sedimento, separou-se a parte líquida para analise de macro e micronutrientes. $\mathrm{Na}$ água coletada foi determinada a concentração de NH4+, NO3-, Pdisp., $\mathrm{Cu}$ e Zn. A parte sólida (sedimentos) foi seca em estufa a $105^{\circ} \mathrm{C}$, para a remoção total da água, e após, foram pesados em balança semi-analítica.

Para a forma NO3-, retirou-se $10 \mathrm{~mL}$ da água e foi realizada a leitura direta no espectrofotômetro. O nitrogênio total foi feito a partir da coleta de $10 \mathrm{~mL}$ de água com adição de aproximadamente $1 \mathrm{~g}$ de Zinco, na qual houve a redução de todo nitrato em amônia. A diferença entre o nitrogênio totale NO3, foi determinada na forma de amônia na água escoada.

A concentração de fósforo foi realizada pela leitura direta de uma quantidade próxima de 10mL no ICP-EOS (Plasma). Para determinação das concentrações de $\mathrm{Cu}$ e $\mathrm{Zn}$, foram adicionadas 3 gotas de HCL $1 \mathrm{~mol} / \mathrm{L}$ no frasco de coleta para decantara argila dis persa. Depois filtrado $10 \mathrm{~mL}$ do sobrenadante. As determinações da concentração dos elementos foram realizadas através da leitura do filtrado no ICP - EOS (Plasma).

Parâmetros Utilizados Para análise da Perda De Solo

Para discussão dos resultados deste trabalho (sólidos totais, amônio - NH4+, nitrato - NO3-, fósforo disponível - Pdisp., zinco - Zn, cobre - $\mathrm{Cu}$ ) utilizou-se os parâmetros estipulados pela resolução 357 do CONAMA (Brasil, 2005) para água doce de Classe I e para ambiente lótico, por apresentarem características comuns às águas superficiais da região do experimento (tabela 7).

Tabela 7. Padrões de qualidade de água para Classe I, Águas Doces.

\begin{tabular}{|ll|}
\hline \multicolumn{1}{|c|}{ PADRÕES } \\
\hline Sólidos Totais & VALOR MÁXIMO \\
\hline PARÂMETROS INORGÂNICOS & $500 \mathrm{mg} / \mathrm{L}$ \\
\hline Cobre dissolvido & $0,009 \mathrm{mg} / \mathrm{L} \mathrm{Cu}$ \\
Fósforo total (ambiente lótico e tributários de ambientesintermediários) & $0,1 \mathrm{mg} / \mathrm{L} \mathrm{P}$ \\
& \\
Nitrato & $10,0 \mathrm{mg} / \mathrm{L} \mathrm{N}$ \\
Nitrogênio amoniacal total & $3,7 \mathrm{mg} / \mathrm{L} \mathrm{N}, \mathrm{para} \mathrm{pH} \leq 7,5$ \\
Zinco total & $0,18 \mathrm{mg} / \mathrm{L} \mathrm{Zn}$ \\
\hline
\end{tabular}

Fonte: Resolução n ${ }^{\circ} 357$ do CONAMA, de 17 de março de 2005.

A classe 1 constitui em águas que podem ser destinadas:a) ao abastecimento para consumo humano, após tratamento simplificado; b) à proteção das comunidades aquáticas; c) à recreação de contato primário, tais como natação, esqui aquático e mergulho d) à irrigação de hortaliças que são consumidas cruas e de frutas que se desenvolvamrentes ao solo e que sejam ingeridas cruas sem remoção de película; e e) à proteção das comunidades aquáticas em Terras Indígenas. $\mathrm{O}$ ambiente lótico refere-se ao ambiente relativo a águas continentais moventes (água corrente) (Brasil, 2005).

\section{Resultados e Discussão}

Perda de Água

As perdas de água em 2010 ocorreram em todos os tratamentos avaliados Controle, AM, DLS100, DLS200, CA100 e CA200, sendo maior no tratamento como dejeto suíno - DLS100 (fig. 3). Os resultados obtidos mostram que provavelmente o dejeto causou um encrostamento superficial com entupimento dos microporos e maior escoamento da água. Os principais efeitos do encrostamento superficial são: redução da infiltração da água, aumento do escoamento, redução da troca gasosa entre solo e atmosfera e interferência na germinação das sementes (Pagliai; Bisdom e Ledin, 1983).

Em 2012, as perdas de água ocorreram nos tratamentos controle, AM, DLS100 e DLS200, sendo a maior perda de água obtida no tratamento com dejeto suíno na maior dose - DLS200 (fig. 3). Uma possível explicação é que o aumento da dose de dejeto pode resultar na obstrução de poros do solo pelos compostos orgânicos sólidos presentes no dejeto e pelo efeito hidrofóbico, que altera o comportamento da hidrologia de superfície. Esse fenômeno promove a repelência da água, dificultando, portanto, a infiltração desta no solo (Bertol et al., 2007).

A aplicação superficial de esterco de animal altera a condutividade hidráulica superficial, promovendo um entupimento do solo a curto prazo que reduz a capacidade de infiltração, por outro lado, a longo prazo condiciona o solo e melhora sua capacidade de infiltração (Roberts e Clanton, 2000).

As partículas de solo possuem cargas negativas livres, as substâncias orgânicas solúveis dos estercos com cargas negativas, promovem repulsão entre as partículas, causando maior dispersão. As partículas dispersas obstruem microporos do solo, dificultando infiltração da água (Barbosa e Miyazawa, 2009). 


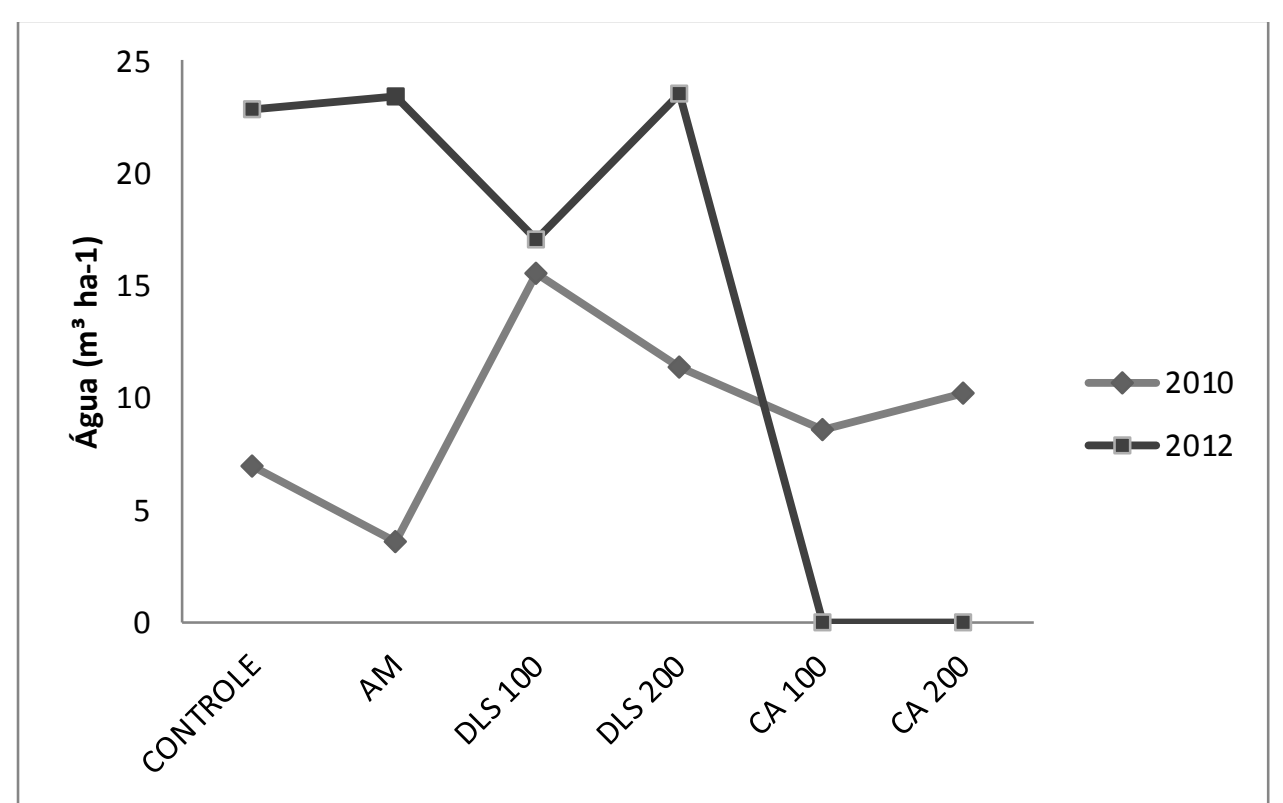

Figura 3. Perdas de água para os anos de 2010 e 2012. Controle = sem adubação; AM= adubação mineral (60 kg N ha-1 através da fórmula 10-30-10); DLS 100 = aplicação de DLS equivalente a $60 \mathrm{~kg} \mathrm{~N}$ ha-1; DLS200 = aplicação de DLS equivalente a $120 \mathrm{~kg} \mathrm{~N}$ ha-1; CA100 = aplicação de CA equivalente a $60 \mathrm{~kg} \mathrm{~N}$ ha-1 e CA200 = aplicação de CA equivalente a $120 \mathrm{~kg} \mathrm{~N}$ ha-1. Média de quatro repetições.

Bertol et al. (2007) ao avaliarem as perdas de solo, água e nutrientes em solo cultivado sob a técnica de semeadura direta e submetido às adubações mineral e orgânica (DLS) Verificaram que as perdas de solo e água nas duas primeiras chuvas foram maiores no solo adubado com DLS do que com adubo mineral. A altura da lâmina de enxurrada no tratamento com DLS foi aproximadamente duas vezes maior do que nos outros dois. Peles (2007) também obteve aumento das perdas de água e solo via escoamento superficial nas maiores doses de DLS.

Oliveira e Parizotto (1994) obtiveram redução da infiltração da água em função do uso de chorume suíno, devido a possível presença de compostos orgânicos hidrofóbicos. Do mes mo modo, avaliando dejeto líquido bovino, Mori et al. (2009) verificaram que a dose igual ou superior a $30 \mathrm{~m}^{3}$ ha-1, seguida imediatamente por chuva de média e alta intensidade (60 e $85 \mathrm{~mm} \mathrm{~h}-1)$ aumentou a taxa de escoamento, e consequentemente, a perda de água e solo.

Nos tratamentos que receberam cama de aviário CA100 e CA200 a perda de água em 2012 foi nula, pois não ocorreu enxurrada com a aplicação da chuva simulada (fig. 3), tornando evidente a capacidade deste adubo em melhorar as propriedades físicas do solo ao longo de quatro anos de experimento, propiciando aumento da infiltração de água no solo, redução do escoamento superficial e consequentemente redução da perda de água, solo e nutrientes, conforme já observado em outras pesquisas.

Lunardi Neto et al. (2008) encontraram melhorias das propriedades físicas dos solos reconstruídos devido à adubação com cama de aviário e a semeadura de Brachiaria brizantha, sendo a recuperação da estabilidade de agregados com aumento do DMP em relação aos outros tratamentos.
Weil e Kroontje (1979) estudando a aplicação de esterco de aves depois de cinco anos em solo argiloso verificaram influência deste resíduo na estrutura do solo da camada arável. Também encontraram diminuição da densidade do solo, aumento dos agregados estáveis em água e do total de agregados e maior teor de umidade. Do mesmo modo, Adeli et al. (2007) observaram aumento da estabilidade de agregados em área que recebeu cama de aviário comparado com áreas que receberam somente fertilizante químico.

Giddens e Barnet (1980) constataramque o aumento da dose de cama de frango retardou o tempo de início da enxurrada e em relação à perda de solo, esta foi maior nas parcelas que não receberam a cama de frango e menor nas parcelas com as maiores doses do resíduo e com pastagem.

Costa et al. (2009) avaliaram a influência da aplicação de cama de frango na recuperação física de um Latossolo Vermelho - textura média sob pastagem degradada e observaram redução nos teores de ADA com o aumento das doses de cama de frango aplicadas, aumento do grau de floculação e redução da densidade do solo. Estes resultados concordam com os resultados de Andreola; Costa e Olszevski (2000) que avaliaram a influência da cobertura vegetal de inverno e das adubações orgânica (esterco de ave) e mineral sobre as propriedades físicas do solo, numa Terra Roxa Estruturada e, concluíram que na camada de 0-10 cm, o adubo orgânico aumentou os macroporos e diminuiu a densidade do solo.

Lima (2007) avaliou atributos físicos de um Latossolo Vermelho textura média, degradado submetido ao uso de pastagem Brachiaria Decumbens, sob diferentes níveis de adubação com dejetos de suínos e cama de aviário e verificaram que profundidade de 0$20 \mathrm{~cm}$ apresentou os melhores resultados na maioria dos 
atributos físicos estudados com aplicação de cama de frango.

Tejada e Gonzalez (2008) encontraram diminuição da densidade do solo com a aplicação de composto de algodão e esterco de aves em comparação com a parcela sem tratamento. Os autores também verificaram a diminuição da perda de solo. Também o trabalho realizado por Obi e Ebo (1995) indicou melhoras nos atributos físicos do solo com a aplicação do dejeto de aves, com menores valores de densidade do solo e de resistência do solo à penetração e maior porosidade total.

As perdas de água na parcela controle em 2010 e 2012 podem estar as sociadas à prática do sistema plantio direto, podendo resultar em uma superfície de solo geralmente consolidada, condição que, com o tempo, favorece a conservação do solo mas, em considerável parte dos casos, desfavorece a conservação da água (Gilles et. al., 2009). Também este resultado explica-s e, em parte, pelo limite de infiltração de água no solo. No solo saturado, a chuva excedente em relação à infiltração transforma-se em escoamento superficial, independentemente do manejo do solo (Bertol et al., 2011).
Além da perda de água no escoamento superficial pode ocorrer também perda de solo e de materiais em suspensão ou dis solução presentes na superfície do solo, ocasionando prejuízos à produção agropecuária com a degradação física, química e biológica do solo, diminuição da fertilidade, assoreamento dos cursos d’água e poluição hídrica com a eutrofização da água pelo $\mathrm{P}$ e contaminação com metais pesados como o $\mathrm{Cu}$ e o $\mathrm{Zn}$, principalmente em terrenos com rampas muito longas e/ou inclinadas, em encostas côncavas e sem práticas de conservação do solo e da água instaladas.

Perda de Solo no Escoamento Superficial, sob chuva simulada

A quantidade de solo transportado no escoamento superficial, em relação ao limite máximo permitido pela resolução 357 do CONAMA foi distinta nos dois anos analisados. As perdas em 2010 (fig. 4) estiveram abaixo do limite de $500 \mathrm{mg} / \mathrm{L}$ estipulado pela legislação para todos os tratamentos estudados. Observa-se que as perdas de solo acompanharam as perdas de água para este ano, apresentando uma correlação.

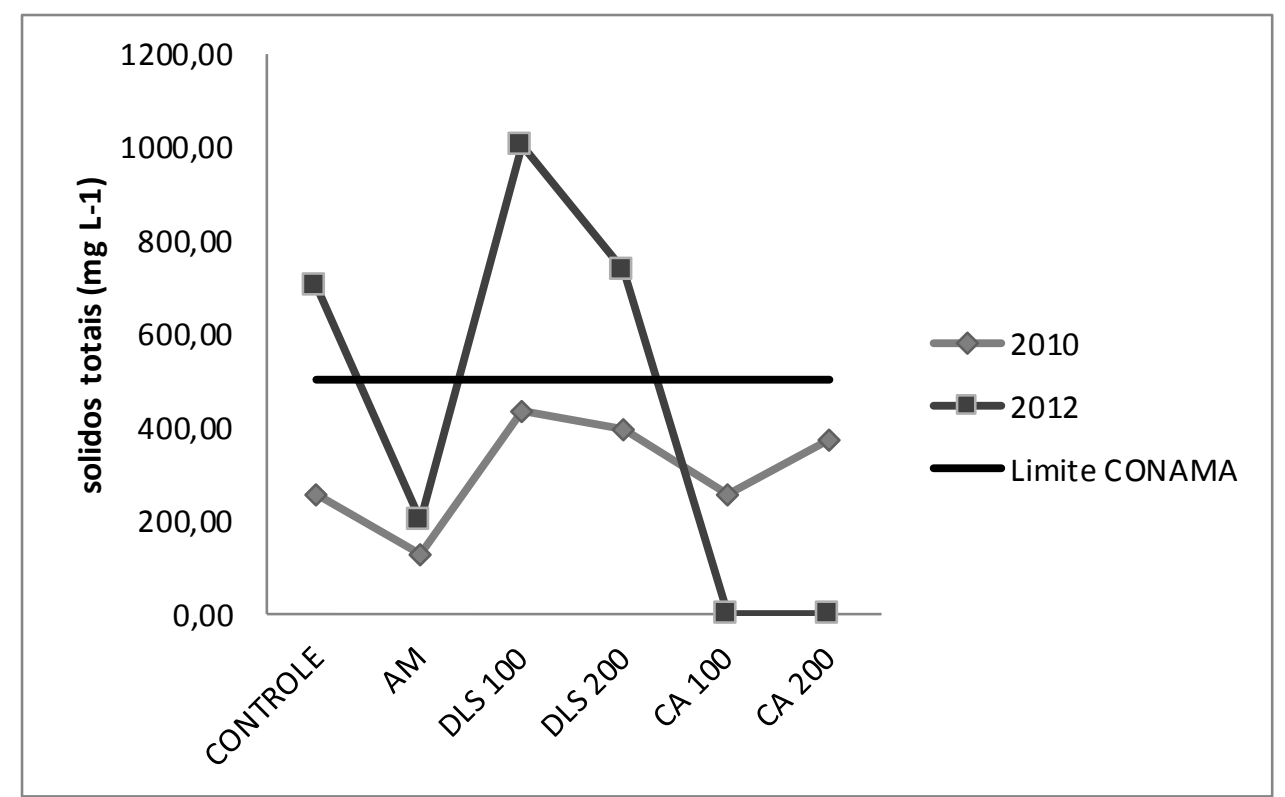

Figura 4. Perdas de solo para os anos de 2010 e 2012 em relação ao limite estabelecido pela resolução 357 do CONAMA (500 mg/L para água doce de classe I). Controle = sem adubação; AM = adubação mineral $(60 \mathrm{~kg} \mathrm{~N}$ ha-1 através da fórmula 10-30-10); DLS 100 = aplicação de DLS equivalente a $60 \mathrm{~kg} \mathrm{~N}$ ha-1; DLS200 = aplicação de DLS equivalente a $120 \mathrm{~kg} \mathrm{~N}$ ha-1; CA100 = aplicação de CA equivalente a $60 \mathrm{~kg} \mathrm{~N}$ ha-1 e CA200 = aplicação de CA equivalente a 120 kg N ha-1. Média de quatro repetições.

Os valores de perda de solo obtidos em 2010 podem estar associados à pequena declividade do terreno da área experimental, que contribui na redução da velocidade da enxurrada e consequente diminuição das perdas de solo por erosão e também à cobertura vegetal deixada pelo plantio direto, que protege o solo contra o impacto das gotas de chuva, diminuindo a desagregação de partículas do solo e seu arraste via escoamento superficial. Vários trabalhos tem reportado a baixa perda de solo no sistema de plantio direto quando comparado ao sistema de preparo convencional (Cassol e Lima, 2003; Guadagnin et. al., 2005; Gilles et. al., 2009; Lemos, 2011; Souza, Madeira e Figueiredo, 2014; Valim e Panachuki, 2010).

Em 2012 as perdas de solo excederam o limite estabelecido pela resolução 357 do CONAMA de 500 $\mathrm{mg} / \mathrm{L}$ para os tratamentos com dejeto líquido suíno DLS 100 e DLS 200 e parcela controle (fig. 4).

A perda de solo na parcela controle pode estar relacionada à menor agregação do solo em função da ausência de adição de matéria orgânica via adubação. Quanto menor os índices de matéria orgânica, menor a 
resistência dos agregados ao impacto das gotas de chuva, estes são facilmente quebrados formando crostas na superfície, dificultando a infiltração, aumentando o escoamento superficial e a perda de solo (Bertoni e Lombardi Neto, 2005).

Já as maiores perdas de solo nos tratamentos com DLS em 2012 podem ser atribuídas possivelmente a um efeito dispersivo do dejeto, levando a um aumento da dispersão da argila, maior desagregação do solo e maiores perdas de solo por erosão, conforme observado em alguns estudos com dejeto de animais (Erthal et al., 2010; Barbosa, Miyazawa e Ruiz, 2011; Condé et al., 2013; Homem et al., 2014).

Erthal et al. (2010) observaram tendência de aumento do percentual de argila dispersa em água ADA na camada superficial com a aplicação de água residuária de bovinocultura, e que esse aumento foi devido ao efeito cumulativo de sódio e potássio nessa camada, favorecendo a dispersão.

Pesquisado água residuária da suinocultura, Condé et al. (2013) verificaram tendência de aumento do percentual de ADA na camada mais profunda. Homem et al. (2014) observaram aumento da porcentagem de ADA com a aplicação deste adubo. Os autores atribuíram o aumento da ADA ao acúmulo de $\mathrm{Na}+$ na solução do solo com a aplicação do resíduo, causando o fenômeno de dispersão de argila.

A presença de alguns constituintes nos dejetos, como o sódio $(\mathrm{Na}+)$ em grande concentração é indesejável. O teor de sódio em solos agrícolas pode aumentar com a adição de efluente, alterando certas características físicas do solo, devido à dispersão de argilas. A solução do solo, quando excessivamente sódica, promove a desagregação e dispersão dos minerais de argila em partículas muito pequenas, que obstruem os poros do solo, promovendo a formação de uma camada superficial selada, reduzindo a infiltração no solo e aumentando os riscos de erodibilidade do solo (Condé et al., 2012).

Em estudo semelhante, realizado na mesma área deste experimento Barbosa, Miyazawa e Ruiz (2011) encontraram maiores perdas de sólidos nas parcelas que receberam as maiores doses de dejetos de suínos e aves.

Pelá (2005) ao avaliar o efeito de adubos orgânicos provenientes de dejetos de bovino em um Latossolo Vermelho Distrófico textura média observou que o composto orgânico diminuiu o DMP em todas as camadas, somente na primeira safra; aumentou a ADA na camada de $0,0-0,10 \mathrm{~m}$ na primeira safra, e nade 0,20 $0,30 \mathrm{~m}$ na segunda safra.

Embora um número grande de trabalhos publicados aponte para melhorias na agregação do solo com a aplicação de DLS (Castro Filho; Costa e Caviglione, 2003; Dortzbach et al., 2008; Lemos, 2011; Mecabô Júnior, 2013; Silva et al., 2011d), alguns pesquisadores tem observado efeito contrário evidenciando a redução da estabilidade de agregados com a adição deste dejeto e de outros dejetos de animais.

Arruda et al. (2010) observaram redução da estabilidade de agregados do solo com a aplicação de 50 e $100 \mathrm{~m}^{3}$ ha-1 de dejeto suíno em relação ao tratamento testemunha sem adubação. Também Veiga et al. (2009) após nove anos de aplicações de $5 \mathrm{~m}^{3}$ ha-1ano-1 de cama de aviário, $40 \mathrm{~m}^{3}$ ha-1ano-1 de dejeto líquido de suíno e $60 \mathrm{~m}^{3}$ ha-1ano-1 de dejeto líquido de bovinos num solo muito argiloso, não encontraram diferenças na densidade e na porosidade do solo, nem na estabilidade de agregados emágua.

Pesquisando a cama de peru Costa et al. (2008) não verificaram efeito das doses na agregação de um Latossolo Vermelho Distrófico típico e nem nos teores de matéria orgânica. Resultado semelhante foi obtido por Pinto et al. (2012) que observaram que o acúmulo crescente das doses de cama de peru não influenciou no estado de agregação do solo, independentemente da camada avaliada.

A ausência de perda de solo nos tratamentos que receberam CA em 2012 (CA100 e CA200) (fig. 4) segue a mesma tendência de perda de água para este mesmo ano, pois não tendo escoamento de água as perdas de solo também foram nulas. Este resultado indica provavelmente a ocorrência de melhoria na agregação do solo com a aplicação da CA, culminando em menor perda de solo e aumento da infiltração conforme já discutido acima.

A manutenção adequada da matéria orgânica em longo prazo resulta em formação de agregados estáveis, contribuindo para o aumento do índice de agregação e diminuição da resistência à penetração (Celik et al., 2010). Também o material orgânico reflete no aumento da fertilidade e diminuição da erodibilidade do solo, prevenindo a perda de solo e água (Bennett, 1955).

A perda de solo e de elementos associados podem causar danos ambientais, como o assoreamento e poluição dos mananciais. No entanto, a própria perda do solo é um dos principais prejuízos, pois é irreversível em curto prazo, uma vez que a natureza gasta cerca de 120 a 400 anos para formar uma camada de solo de $1 \mathrm{~cm}$ de espessura (Tavares Filho, 2013).

\footnotetext{
Concentração de Amônio - NH4+ no escoamento superficial

Para as avaliações realizadas em 2010, as concentrações de NH4+ no escoamento superficial ultrapas saram o limite máximo de $3,7 \mathrm{mg} / \mathrm{L}$ estabelecido pela resolução 357 do CONAMA (para água doce de classe $\mathrm{I}$, para $\mathrm{pH} \leq 7,5$ ) (Brasil 2005), em todos os tratamentos avaliados - Controle, AM, DLS100, DLS200, CA100 e CA200 (fig. 5).
} 


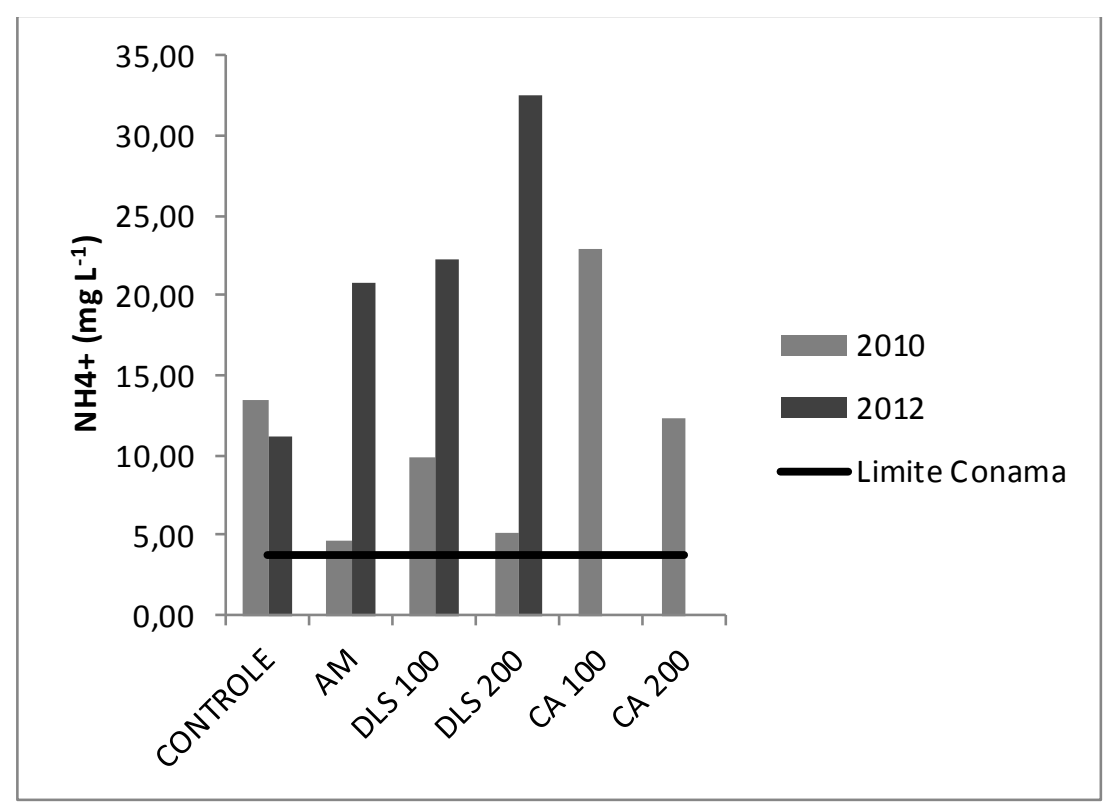

Figura 5. Concentração de NH4+ para os anos de 2010 e 2012. Controle = sem adubação; AM = adubação mineral (60 kg N ha-1 através da fórmula 10-30-10); DLS 100 = aplicação de DLS equivalente a $60 \mathrm{~kg}$ N ha-1; DLS200 = aplicação de DLS equivalente a $120 \mathrm{~kg} \mathrm{~N}$ ha-1; CA100 = aplicação de CA equivalente a $60 \mathrm{~kg} \mathrm{~N}$ ha-1 e CA200 = aplicação de CA equivalente a $120 \mathrm{~kg} \mathrm{~N}$ ha-1. Média de quatro repetições. $\mathrm{O}$ valor limite para o Nitrogênio amoniacal total estipulado pela resolução ${ }^{\circ} 357$ do CONAMA é de $3,7 \mathrm{mg} / \mathrm{L}$ para água doce de classe I, para $\mathrm{pH} \leq 7,5$.

Nas avaliações realizadas em 2012, as concentrações de NH4+ excederam o limite máximo nos tratamentos Controle, AM, DLS100 e DLS200, já nos tratamentos com cama de aviário - CA100 e CA200 não houve perda do nutriente devido à ausência de enxurrada com a aplicação da chuva simulada (fig. 5).

Neste estudo verificou-se que as concentrações de NH4+ encontraram-se mais elevadas que as concentrações de NO3- em 2012 (figs. 5 e 6), provavelmente devido ao fato de não ter ocorrido uma completa nitrificação e também pela quantidade de nitrogênio adicionado. Os resultados de concentração de NH4+ no escoamento superficial de 2010 e 2012 deixam claro o potencial poluidor dessa forma de $\mathrm{N}$ caso a solução escoada alcance os corpos d'água superficiais, indicando necessidade de controle da enxurrada.

O amônio NH4+ em altas concentrações é um indicativo de que pode ocorrer uma oxidação para nitrato (processo de nitrificação), aumentando as sim os teores dessa substância no meio (Cabral, 2007).

As perdas de NH4+ no escoamento superficial em 2010 e 2012 deve-se, provavelmente, ao fato de que o amônio tende a ficar retido no solo através de mecanismos de troca de cátions, sendo adsorvido nas partículas e assim mais suscetível às perdas por erosão do que por lixiviação (Hooda et al., 2000). O NH4+ tende a ser adsorvido nas partículas do solo e, assim, perde-se mais por processos erosivos, enquanto o NO3-
, em razão da sua baixa reatividade e alta mobilidade no perfil, é preferencialmente perdido por lixiviação (Timofiecsyk et al., 2012).

No tratamento controle sem aplicação de adubo observam-se perdas elevadas de NH4+ (fig. 5), ressaltando o transporte de nutrientes em áreas manejadas no sistema de plantio direto. A técnica de semeadura direta tem proporcionado acúmulo de nutrientes na superfície do solo, pela não inversão da sua camada arável, o que favorece a concentração de nutrientes na enxurrada. A erosão hídrica, por ser seletiva, preferencialmente transporta os sedimentos mais finos, de menor diâmetro e de baixa densidade, constituídos, sobretudo, de coloides minerais e orgânicos e normalmente enriquecidos de elementos minerais (Bertol et al., 2007).

Concentração de nitrato - NO3- no escoamento superficial

Para as avaliações realizadas em 2010, as concentrações de NO3- na solução do escoamento superficial foram superiores ao valor crítico de $10 \mathrm{mg} / \mathrm{L}$ estabelecido pela resolução 357 do CONAMA (para água doce de classe I) nos tratamentos AM, DLS100, DLS200 e CA100 (fig. 6), o que significa risco de contaminação ambiental caso este nutriente atinja as águas superficiais. 


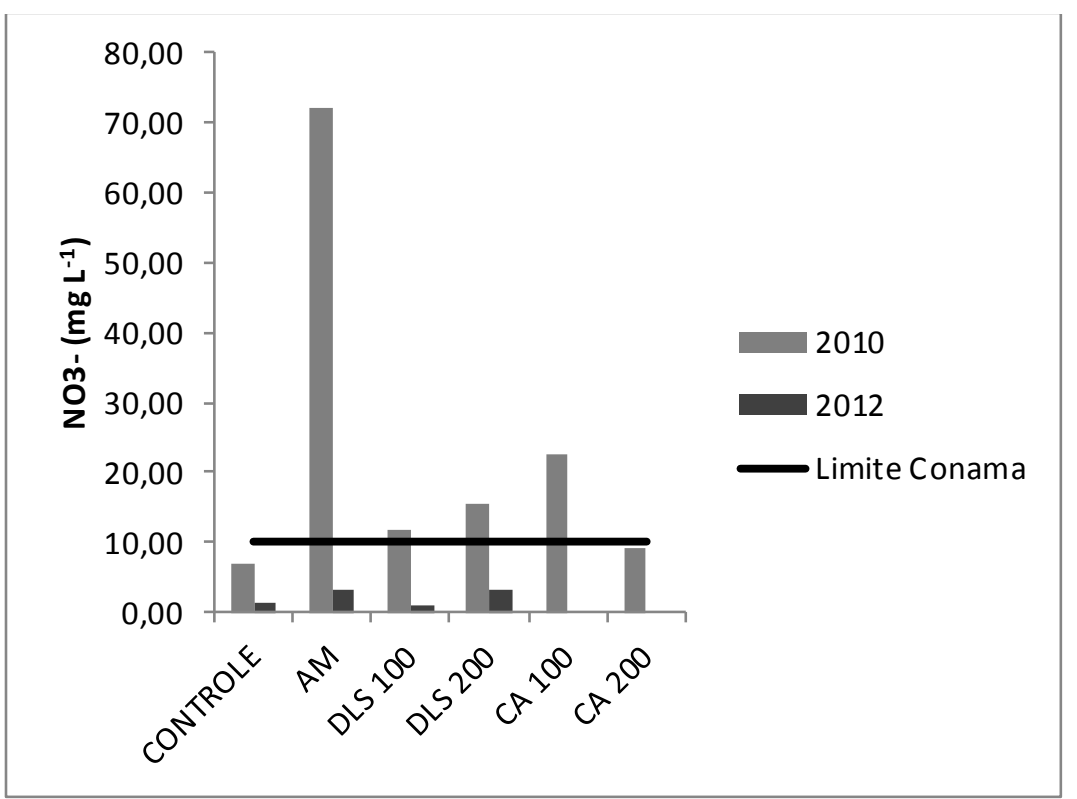

Figura 6. Concentração de NO3- para os anos de 2010 e 2012. Controle = sem adubação; AM = adubação mineral (60 kg N ha-1 através da fórmula 10-30-10); DLS 100 = aplicação de DLS equivalente a 60 kg N ha-1; DLS200 = aplicação de DLS equivalente a $120 \mathrm{~kg} \mathrm{~N}$ ha-1; CA100 = aplicação de CA equivalente a $60 \mathrm{~kg} \mathrm{~N}$ ha-1 e CA200 = aplicação de CA equivalente a $120 \mathrm{~kg} \mathrm{~N}$ ha-1. Média de quatro repetições. O valor limite para NO3- estipulado pela resolução $\mathrm{n}^{\circ} 357$ do CONAMA é de $10 \mathrm{mg} / \mathrm{L}$ para água doce de classe I.

Considerando os valores obtidos em 2010, a água escoada foi uma fonte potencial de contaminação da água superficial por NO3-. O nitrato é considerado a principal forma de nitrogênio as sociada à contaminação da água pelas atividades agrícolas (Jadoski et al., 2010). O ânion nitrato caracterizado por ser fracamente retido nas cargas positivas dos coloides, tende a permanecer mais em solução, principalmente nas camadas superficiais do solo, nas quais a matéria orgânica acentua o caráter eletronegativo na fase sólida (repelindo o nitrato), e os fosfatados ocupamas cargas positivas disponíveis, deixando o nitrato propenso à lixiviação e ao escoamento superficial, levando à eutrofização das fontes superficiais e subterrâneas da água (Resende, 2002).

A eutrofização consiste no enriquecimento das águas por nutrientes que alimentam o crescimento vegetal, o que favorece a proliferação exagerada de algas e plantas aquáticas. Quando estas plantas e algas morrem e se decompõem, níveis de oxigênio dissolvido em lagos e córregos são esgotados, o que pode levar ao aparecimento de odores, mortandade de peixes, e uma degradação geral do valor estético e recreativo do meio ambiente, restrição de uso da água para a pesca, recreação e indústria, impalatabilidade de água potável, formação de agentes cancerígenos durante cloração da água e comprometimento neurológico em humanos (Bundy et al., 2001; Resende, 2002; Shigaki; Sharpley e Prochnow 2006a).

Algumas cepas de cianobactérias, ao morrerem, podem liberar neurotoxinas e hepatotoxinas que afetam a saúde humana, seja pela ingestão da água ou pelo contato primário em atividades de recreação. Também, a presença dessas algas propicia a formação de trialometanos (produto da reação entre a matéria orgânica e o cloro) durante o processo de cloração da água. A remoção de cianobactérias bem como de toxinas e trialometanos da água destinada para consumo humano exige técnicas sofisticadas, as quais consequentemente elevam os custos com o seu tratamento (Costa, 2008).

Além da eutrofização, as altas concentrações de nitrato na água podem causar problemas à saúde humana, como diminuição na capacidade do sangue para transportar oxigênio - metahemoglobinemia (síndrome do bebê azul), produção de nitros aminas (que geralmente causam câncer), doenças respiratórias, disfunção da glândula tireoide e abortos fetais na pecuária (Nyakatawa, et al., 2001; Jadoski et al., 2010).

Para as avaliações realizadas em 2012, as concentrações de NO3- no escoamento superficial estiveram abaixo do valor crítico de $10 \mathrm{mg} / \mathrm{L}$ estabelecido na legislação para todos os tratamentos avaliados (fig. 6), indicando maior lixiviação deste nutriente, diminuindo assim, o escoamento superficial desse poluente. Outra possibilidade para menor concentração de NO3- em 2012 pode estar as sociado ao fato de não ter ocorrido uma completa nitrificação do nitrogênio adicionado ao solo. No entanto, se por um lado não existe problema de poluição por nitrato nas águas superficiais, por outro pode estar ocorrendo contaminação das águas subterrâneas, porém neste estudo não foram avaliados as concentrações de nutrientes no lixiviado.

O nitrato é livremente móvel na solução do solo e é, portanto, potencialmente vulnerável a lixiviar abaixo da zona de enraizamento com a água que se des loca através do solo (Hooda et al., 2000).

Trabalhos tem relatado a percolação do NO3- em áreas que receberam dejeto de animais e contaminação ambiental por este elemento. Aita, Port e Giacomini (2008) avaliando o acúmulo e o deslocamento de N- 
NO3 no solo após a aplicação de doses de dejeto líquido suíno, verificaram que as quantidades de N-NO3 e a sua percolação no solo aumentaram rapidamente após a aplicação dos dejetos, principalmente na maior dose aplicada de $80 \mathrm{~m} 3$ ha-1. Esse comportamento foi observado também por Fey et al. (2010) estudando a lixiviação de nitrato devido à aplicação de dejetos suínos e verificaram que no LVef os tratamentos com 60 e 150 $\mathrm{m} 3$ ha-1 de dejeto não tratado e $150 \mathrm{~m} 3$ ha-1 de dejeto preestabilizado, o deslocamento foi significativo, com acúmulo de nitrato na camada 40 a $60 \mathrm{~cm}$.

Caovilla et. al (2005) conduziram um trabalho com água residuária da suinocultura em um Latossolo Vermelho Distroférrico típico e verificaram que o tratamento que recebeu maior concentração do resíduo apresentou as maiores concentrações de nitrato, potás sio e sais totais nos lixiviados. Estudando o mesmo resíduo Anami et al. (2008) verificaram que o íon nitrato apresentou elevado potencial de percolação, ao contrário do que ocorreu com o íon fosfato, que apresentou baixo potencial de contaminação.

Basso et. al. (2005) ao avaliar a percolação de nitrogênio e fósforo em área submetida a aplicações sistemáticas de dejeto líquido de suínos constataramque com o aumento da dose de dejeto ocorreu o incremento nas concentrações de nitrato na água percolada. Também Kingery et al. (1994) estudaram o impacto da aplicação de cama de frango e verificaram acumulação significativa de nitrato na profundidade de $60 \mathrm{~cm}$.

Concentração de fósforo disponível Pdisp. no escoamento superficial

Para as avaliações realizadas em 2010, as concentrações de $\mathrm{P}$ disponível no escoamento superficial estão abaixo do valor crítico estipulado pela resolução 357 do CONAMA de $0,1 \mathrm{mg} / \mathrm{L}$ (padrão estipulado para água doce de classe I, ambiente lótico), para todos os tratamentos avaliados, ocorrendo perdas deste elemento somente no tratamento com adubação mineral - AM (fig. 7).

Nas avaliações realizadas em 2012, as concentrações de $\mathrm{P}$ disponível no escoamento superficial estão muito acima do valor de $0,1 \mathrm{mg} / \mathrm{L}$ estabelecidos na legis lação brasileira (fig. 7). As perdas ocorreram nos tratamentos controle, adubação mineral - AM e dejeto líquido suíno (DLS100 e DLS200), sendo maior na maior dose de DLS - DLS200.

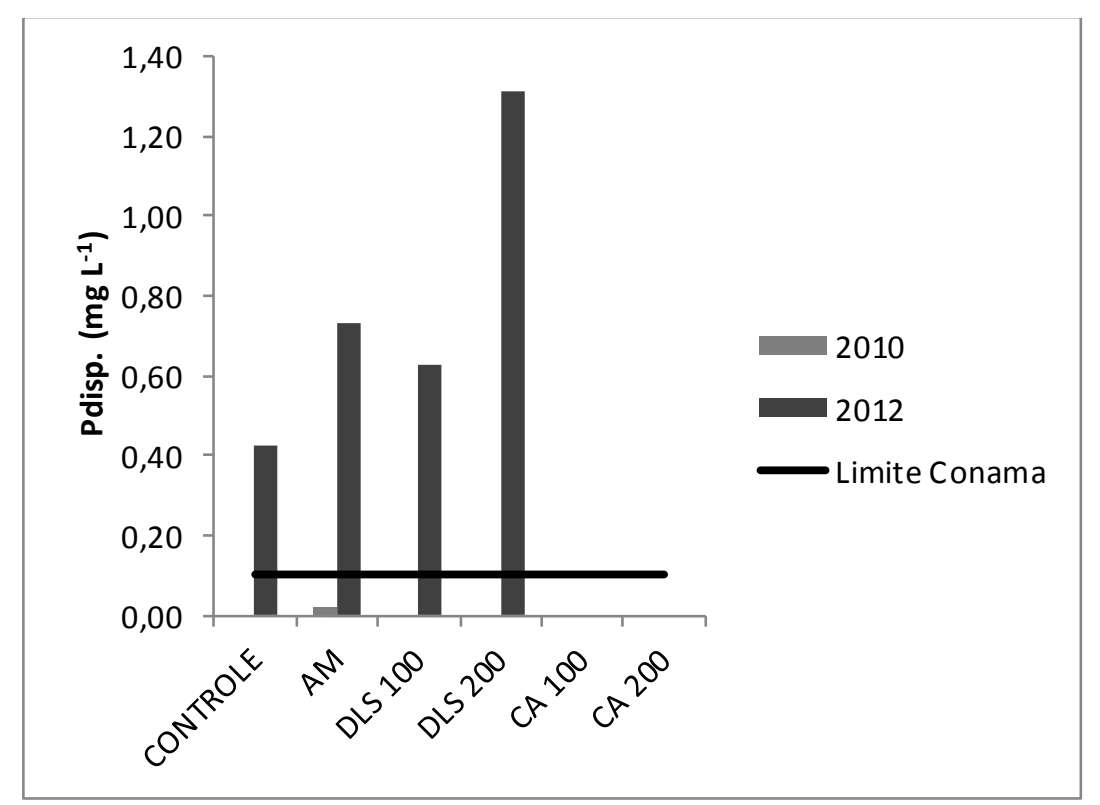

Figura 7. Concentração de $\mathrm{P}$ disp. para os anos de 2010 e 2012. Controle = sem adubação; $A M=$ adubação mineral $(60$ kg N ha-1 através da fórmula 10-30-10); DLS 100 = aplicação de DLS equivalente a $60 \mathrm{~kg} \mathrm{~N}$ ha-1; DLS200 = aplicação de DLS equivalente a $120 \mathrm{~kg} \mathrm{~N}$ ha-1; CA100 = aplicação de CA equivalente a $60 \mathrm{~kg} \mathrm{~N}$ ha-1 e CA200 = aplicação de CA equivalente a $120 \mathrm{~kg} \mathrm{~N}$ ha-1. Média de quatro repetições. O valor limite para $\mathrm{P}$ total estipulado pela resolução $\mathrm{n}^{\circ} 357$ do CONAMA é de $0,1 \mathrm{mg} / \mathrm{L}$ para água doce de classe I, ambiente lótico.

Es sas concentrações de P disponível em 2012 podem ser, em partes, devido ao fato de que a aplicação de fertilizantes orgânicos ao longo do tempo promove alterações nas frações de $\mathrm{P}$ no solo, assim como a saturação dos sítios de adsorção por esse elemento especialmente na forma inorgânica, resultando numa menor capacidade de adsorção de $\mathrm{P}$ no perfil. Is to ocorre de tal modo, que a energia de ligação do $\mathrm{P}$ com os coloides do solo diminua, aumentando sua disponibilidade às plantas e potencializando as transferências de fósforo por escoamento superficial e percolação (Hentz e Carvalho, 2014).

Outra explicação deve-se ao fato de que o fósforo é transportado em maior quantidade pelo escoamento superficial do que pelo fluxo subterrâneo, pois é fortemente adsorvido pelas partículas do solo, reduzindo sua mobilidade. Desta forma, o P tende a acumular no local de aplicação e se transferido apenas quando a porção do solo onde está localizado é removida (Doblinski et al., 2010). 
A forma como o P é encontrado no dejeto e o manejo adotado pode contribuir com grandes acúmulos de $\mathrm{P}$ disponível nas camadas superficiais do solo. O P encontrado nos dejeto encontra-se predominantemente na forma inorgânica, prontamente disponível para as plantas (Lourenzi et al., 2014b). Também a ausência de revolvimento do solo no plantio direto tem proporcionado acúmulo de nutrientes na superfície do solo, favorecendo a concentração de nutrientes na enxurrada (Bertol et al., 2007).

Resultados semelhantes aos obtidos nesse estudo foram encontrados em outras pesquisas que avaliaram dejeto de animais. Lourenzi et al. (2014b) estudaram o efeito de sucessivas aplicações de fontes orgânicas (dejeto suíno e bovino) e mineral sobre o teor dis ponível, o escoamento superficial e a percolação de formas de P em um Argissolo Vermelho manejado sob sistema plantio direto. Os autores observaram que as aplicações de fontes de nutrientes ao longo dos anos proporcionaram incremento e migração de P-disponível no perfil do solo, refletindo em transferências de $\mathrm{P}$ por escoamento superficial e percolação, especialmente no solo com a aplicação de dejeto suíno, onde foi realizad a a maior adição do nutriente.

Estudando o efeito da aplicação de diferentes fontes de fósforo solúvel em água no transporte de $\mathrm{P}$ no escoamento superficial Shigaki, Sharpley e Prochnow (2006a) observaram um aumento drástico no fósforo dissolvido reativo, no fósforo total e na perda cumulativa com o aumento da fonte de fósforo solúvel em água.

Peles (2007) avaliou a perda de nutrientes via escoamento superficial com a aplicação de doses de dejeto líquido de suínos e gesso e encontrou aumento da concentração de N-NH4, $\mathrm{N}$ total, $\mathrm{P}$ solúvel, $\mathrm{P}$ particulado e $\mathrm{P}$ total na água, sendo que os maiores valores corresponderam às maiores doses de dejeto suíno, concordando com os resultados de Basso (2003) que verificou que a concentração de fósforo disponível na solução do es coamento superficial, foi dependente da quantidade de dejeto suíno aplicado, sendo maior nas maiores doses. Resultado semelhante foi obtido por Allen e Mallarino (2008) que encontraram aumento da concentração e carga de $\mathrm{P}$ no escoamento após $24 \mathrm{~h}$ da aplicação de esterco líquido de suínos, semincorporação ao solo com o aumento das doses do dejeto. $\mathrm{O}$ mesmo foi encontrado por Gessel et al. (2004) que verificaram maior perda de $\mathrm{P}$ dissolvido no escoamento com o aumento da taxa de aplicação do dejeto suíno. Também Dieter (2009) constatou que o fósforo solúvel presente no escoamento superficial é dependente da dose de água residuária de suinocultura aplicada, sendo maior na maior dose (200 $\mathrm{m}^{3}$ ha-1).

Mori et al. (2009) verificaram aumento da concentração de $\mathrm{P}$ total, solúvel e particulado no escoamento com valores acima dos níveis críticos relacionados com a eutrofização com a aplicação de dejeto líquido bovino.

Guardini et al. (2012) avaliaram o acúmulo e o potencial contaminante do $\mathrm{P}$ em um solo que recebeu dejetos de suínos na forma de dejetos líquidos e cama sobreposta. Os autores verificaram que a adição de cama sobreposta de suínos no solo ao longo de oito anos aumentou a quantidade de $\mathrm{P}$ na solução na camada superficial do solo.

Kleinman et al. (2002) obtiveram maiores concentrações de P solúvel e $\mathrm{P}$ total no escoamento nas parcelas que receberam os adubos mineral (fosfato de diamônio) e orgânicos (esterco bovino, esterco de ave e chorume suíno) em relação à parcela controle sem tratamento. As concentrações de $\mathrm{P}$ solúvel e $\mathrm{P}$ total no escoamento dos solos tratados com esterco bovino foram superiores à da parcela controle.

Smith et al. (2007) constataramque quando aplicado na superfície de pastagem a mesma dose de fertilizante, o dejeto líquido suíno demonstrou um grande risco à qualidade da água um dia após a aplicação do resíduo em relação ao fertilizante mineral e cama de frango. À medida que aumentou o tempo de aplicação do esterco suíno e a chuva simulada os riscos de perda de $\mathrm{P}$ e $\mathrm{N}$ para a água de escoamento diminuíram.

Os resultados obtidos em 2012 para os tratamentos controle, AM e DLS 100 e DLS 200 revelam risco de eutrofização das águas superficiais pelo $\mathrm{P}$ caso a água escoada atinja os corpos d'água. $\mathrm{O}$ uso excessivo de fósforo leva a uma diminuição da absorção de cálcio e aumenta a liberação de cálcio dos ossos agravando o risco de osteoporose (Gabriel et al., 2012).

\section{Concentrações de $\mathrm{Cu}$ e $\mathrm{Zn}$ no es coamento superficial}

Nas avaliações realizadas em 2010, as concentrações de $\mathrm{Cu}$ no escoamento superficial (fig. 8) estão bem acima do limite de $0,009 \mathrm{mg} / \mathrm{L}$ estabelecido pela resolução 357 do CONAMA (para água doce de Classe I) para todos os tratamentos estudados. Estas perdas podem ser um reflexo da baixa mobilidade do $\mathrm{Cu}$ no perfil. O Cu dentre os micronutrientes é o menos móvel no solo devido à sua forte adsorção nos coloides orgânicos e inorgânicos do solo (Novais, et al., 2007).

Já, nas avaliações realizadas em 2012, as concentrações de $\mathrm{Cu}$ na enxurrada foram superiores ao valor de $0,009 \mathrm{mg} / \mathrm{L}$ estipulado pela legis lação brasileira para os tratamentos controle, AM, DLS100 e DLS200 (fig. 8), sendo que a ausência de $\mathrm{Cu}$ nos tratamentos com cama de aviário CA100 e CA200 (fig. 8) deve-se ao fato de que não ocorreu escoamento superficial nestas parcelas com a aplicação de chuva simulada, porém em 2010 quando ocorreu a enxurrada, as concentrações deste elemento mostram alto potencial contaminante.

Os resultados de 2010 e 2012 indicam risco de contaminação ambiental por $\mathrm{Cu}$ caso o material escoado atinja os mananciais de águas superficiais. $\mathrm{O} \mathrm{Cu}$ em excesso tende a se acumular no sangue e com isto es gotar as reservas de zinco do cérebro (Gabriel et al., 2012).

A elevada concentração de metais na água, sedimentos e organismos aumenta a vulnerabilidade da saúde humana por meio da bioacumulação. Essa vulnerabilidade resulta na contaminação por metais pesados através de duas formas: beber água contaminada que passou por tratamento inadequado, expondo a população à ingestão de metais em doses 
toleráveis, ou a ingestão através de alimentos contaminados, como por exemplo, o peixe (CARVALHO; ORSINE, 2011).

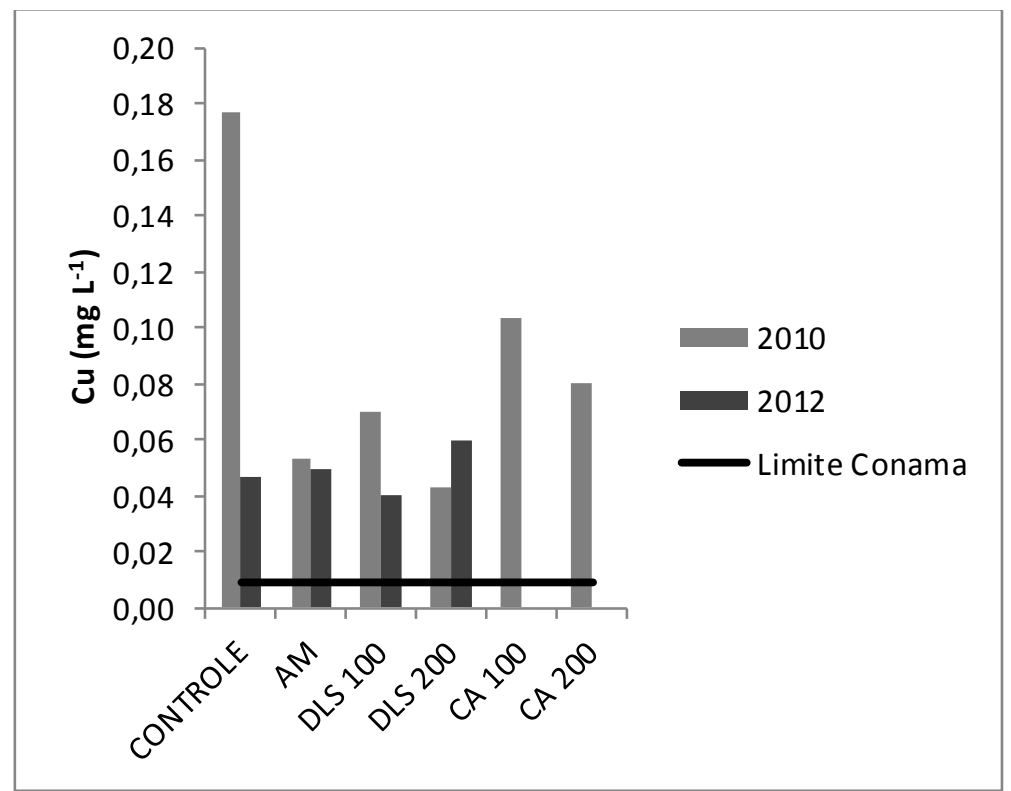

Figura 8. Concentração de $\mathrm{Cu}$ para os anos de 2010 e 2012. Controle = sem adubação; $\mathrm{AM}=$ adubação mineral $(60 \mathrm{~kg} \mathrm{~N}$ ha-1 através da fórmula 10-30-10); DLS 100 = aplicação de DLS equivalente a $60 \mathrm{~kg} \mathrm{~N}$ ha-1; DLS200 = aplicação de DLS equivalente a $120 \mathrm{~kg} \mathrm{~N}$ ha-1; CA100 = aplicação de CA equivalente a $60 \mathrm{~kg} \mathrm{~N}$ ha-1 e CA200 = aplicação de CA equivalente a $120 \mathrm{~kg} \mathrm{~N}$ ha-1. Média de quatro repetições. O valor limite para $\mathrm{Cu}$ dissolvido estipulado pela resolução $\mathrm{n}^{\circ}$ 357 do CONAMA é de 0,009 mg/L para água doce de classe I.

Para as avaliações realizadas em 2010, as concentrações de Zn no escoamento superficial (fig. 9) ultrapassaramo limite máximo de $0,18 \mathrm{mg} / \mathrm{L}$ (para água doce de classe I) estabelecido pela resolução 357 do CONAMA para todos os tratamentos avaliados. Estas concentrações possivelmente devem-se à baixa mobilidade do Zn no perfil do solo, fazendo com que o mesmo se acumule na superfície do terreno e seja transportado pela enxurrada, evidenciando o potencial contaminante deste micronutriente

O $\mathrm{Zn}$ pode causar irritação e corrosão do trato intestinal, podendo ainda levar a necrose renal ou nefrite, nos casos mais severos (Alves et al., 2010).

Para as avaliações realizadas em 2012, as concentrações de $\mathrm{Zn}$ no material escoado estiveram muito menores do que $0,18 \mathrm{mg} / \mathrm{L}$ valor máximo estabelecido pela legislação para os tratamentos controle, AM, DLS100 e DLS200 (fig. 9). Este resultado pode indicar a ocorrência de migração deste elemento no perfil do solo, devido ao maior acúmulo deste elemento, diminuindo sua disponibilidade na camada superficial e na solução escoada. O Zn é um dos metais pesados mais móveis no solo (Novais, et al., 2007). Em decorrência da menor afinidade do $\mathrm{Zn}$ pelos grupos funcionais das partículas de tamanho coloidal presentes no solo, a migração de $\mathrm{Zn}$ no perfil do solo passa a ser muito mais intensa do que a do $\mathrm{Cu}$ (Girotto et al. 2010a).

Nos tratamentos CA100 e CA200 em 2012 não ocorreram perdas de $\mathrm{Zn}$ similarmente ao explicado para o $\mathrm{Cu}$, devido à ausência de escoamento superficial nestas parcelas neste ano (fig. 9). No entanto, quando ocorreu a enxurrada nas parcelas adubadas com cama de aviário em 2010 as concentrações de Zn apresentaram potencial contaminante (fig. 9), indicando que a aplicação deste resíduo deve ser monitorada para não causar contaminação ambiental das águas superficiais. 


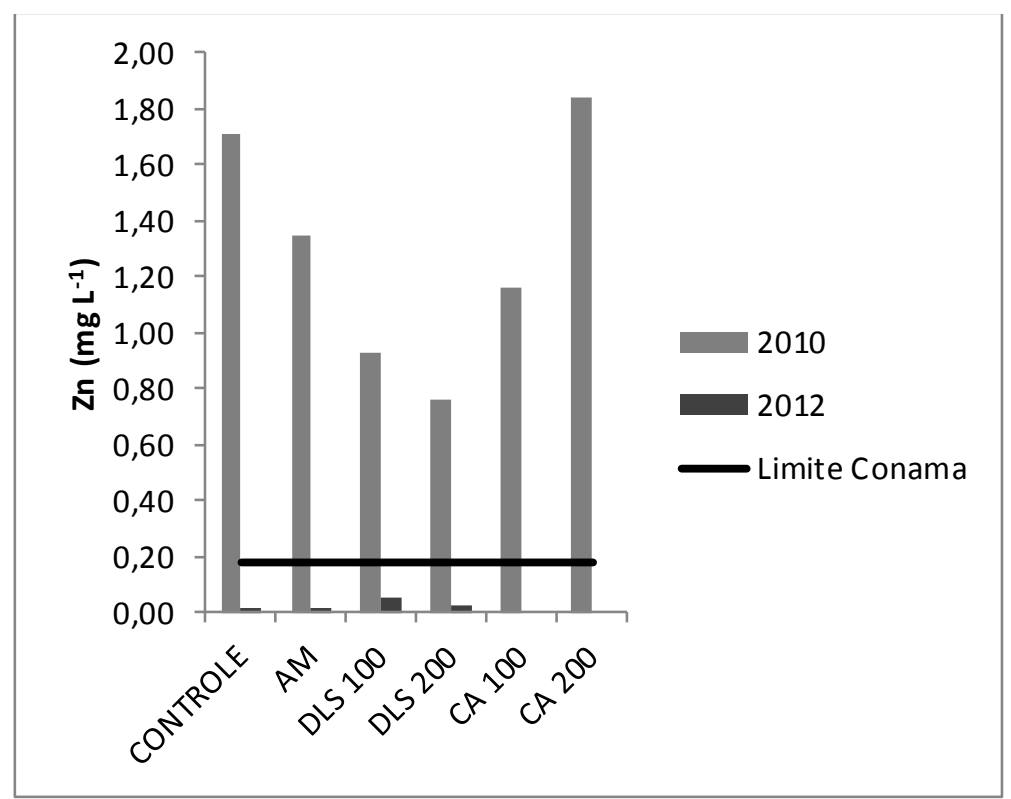

Figura 9. Concentração de Zn para os anos de 2010 e 2012. Controle = sem adubação; AM = adubação mineral (60 kg N ha-1 através da fórmula 10-30-10); DLS 100 = aplicação de DLS equivalente a $60 \mathrm{~kg} \mathrm{~N} \mathrm{ha-1;} \mathrm{DLS200} \mathrm{=} \mathrm{aplicação} \mathrm{de}$ DLS equivalente a $120 \mathrm{~kg} \mathrm{~N}$ ha-1; CA100 = aplicação de CA equivalente a $60 \mathrm{~kg} \mathrm{~N}$ ha-1 e CA200 = aplicação de CA equivalente a $120 \mathrm{~kg} \mathrm{~N}$ ha-1. Média de quatro repetições. O valor limite para Zn total estipulado pela resolução $\mathrm{n}^{\circ} 357$ do CONAMA é de $0,18 \mathrm{mg} / \mathrm{L}$ para água doce de classe I.

As concentrações de $\mathrm{Cu}$ e $\mathrm{Zn}$ no escoamento superficial eram esperadas, pois os metais pesados como o $\mathrm{Cu}$ e o $\mathrm{Zn}$, presentes nos dejetos de animais, devido à baixa mobilidade no perfil do solo, tendem a acumularse na camada superficial e, portanto, apresentam baixo potencial de lixiviação, contudo, aplicações excessivas de dejeto podem ocasionar perdas em subsuperfície (Bertol et al., 2010).

Os micronutrientes $\mathrm{Cu}$ e o $\mathrm{Zn}$ por não serem biodegradáveis, acumulam-se em diversas cadeias alimentares, incluindo as cadeias das quais os humanos fazem parte, podendo causar doenças sérias, como por exemplo, o câncer (Lima-Silva et al., 2002).

Comparativamente aos outros tratamentos as concentrações de $\mathrm{Cu}$ e $\mathrm{Zn}$ em 2010 (fig. 8 e 9) foram muito elevadas na parcela controle, provavelmente devido ao elevado teor destes micronutrientes em condições naturais na superfície do solo. Solos derivados de rochas ígneas básicas, como o solo deste experimento, são mais ricos em $\mathrm{Cu}$ e $\mathrm{Zn}$ do que os solos oriundos de rochas sedimentares (Novais et al., 2007). Resende et al. (2007) apresentamo teor total de $\mathrm{Cu}$ e $\mathrm{Zn}$ para o Latossolo Vermelho Distroférrico localizado em Londrina-Pr, sendo $238 \mathrm{mg} \mathrm{Kg}-1$ de $\mathrm{Cu}$ e $91 \mathrm{Kg}-1$ de $\mathrm{Zn}$. Os valores de $\mathrm{Cu}$ encontram-se bem acima dos valores típicos registrados para solos (30 mg Kg-1). Além disso, as concentrações do $\mathrm{Cu}$ e $\mathrm{Zn}$ nos demais tratamentos também podem ser reflexo do plantio direto e da adubação com dejeto de animais.

As perdas de $\mathrm{Cu}$ e $\mathrm{Zn}$ no escoamento superficial encontradas neste trabalho também são mostradas em outras pesquisas com dejeto de animais. Lourenzi et al. (2008) obtiveram maiores transferências de $\mathrm{Cu}$ e $\mathrm{Zn}$ por escoamento superficial na forma solúvel nos primeiros eventos chuvosos após a aplicação do dejeto líquido suíno. Em avaliações realizadas no mesmo experimento
Girotto et al. (2010a) constataramaumento dos teores de $\mathrm{Cu}$ e $\mathrm{Zn}$ no solo das camadas superficiais, com migração de $\mathrm{Cu}$ até a profundidade de $12 \mathrm{~cm}$ e de $\mathrm{Zn}$ até $10 \mathrm{~cm}$.

Pesquisando aplicações de dejeto líquido e cama sobreposta de suínos Tiecher et al. (2013) encontraram em doses equivalentes a $90 \mathrm{~kg}$ ha- 1 de $\mathrm{N}$ aumento do conteúdo de $\mathrm{Cu}$ disponível e $\mathrm{Zn}$ na camada superficial do solo e quando o dobro dessa dose foi aplicado o $\mathrm{Cu}$ e Zn migraram para uma profundidade de $15 \mathrm{~cm}$.

Trabalho realizado por Dal Bosco et. al (2008) indicou maior concentração de $\mathrm{Cu}$ no material escoado em parcelas tratadas com a maior dose de água residuária de suinocultura. Bem como constatado por Girotto et al. (2010b) que verificaram aumento significativo das quantidades de $\mathrm{Cu}$ e, principalmente, de $\mathrm{P}$ transferido por escoamento chegando a 2,3 e 92,8 vezes maior, respectivamente, com aplicações sucessivas de dejeto líquido de suínos.

Smanhotto et al. (2010) ao es tudarem a concentração de $\mathrm{Cu}$ e $\mathrm{Zn}$ no material percolado com a aplicação de água residuária de suinocultura, verificaram que as transferências de $\mathrm{Cu}$ e de $\mathrm{Zn}$ por percolação foram pouco expressivas. Esses dados se assemelham aos obtidos por Bertol et al. (2010) que ao estudarem a mobilidade de $\mathrm{P}, \mathrm{Cu}$ e $\mathrm{Zn}$ em colunas de solo submetido às adubações mineral e dejeto líquido suíno verificaram que os elementos tiveram baixa mobilidade no solo, independentemente do tipo de adubo utilizado, concentrando-se na camada de 0 a $2,5 \mathrm{~cm}$.

\section{Conclusões}

Baseando-se nos dados apresentados e discutidos neste trabalho apresenta-se as seguintes conclusões: 
1 - As perdas de água em 2010 ocorreram em todos os tratamentos avaliados. Em 2012, as perdas de água ocorreram nos tratamentos Controle, AM, DLS100 e DLS200, sendo que em ambas avaliações as perdas foram maiores nos tratamentos com DLS, indicando a necessidade de maior controle de aplicação deste esterco.

2 - As perdas de solo no escoamento superficial em 2010 não excederam o limite máximo de $500 \mathrm{mg} / \mathrm{L}$ permitido pelo legis lação. Em 2012 as perdas de solo excederam o limite nos tratamentos com dejeto líquido suíno (DLS100 e DLS200) e no Controle.

3 - As concentrações de $\mathrm{NH}_{4}{ }^{+}$na água de escoamento superficial em 2010 ultrapassaram o limite máximo de $3,7 \mathrm{mg} / \mathrm{L}$ permitido pela legislação em todos os tratamentos avaliados. Em 2012 as concentrações de $\mathrm{NH}_{4}{ }^{+}$excederam o limite nos tratamentos Controle, AM, DLS100 e DLS200.

4 - As concentrações de $\mathrm{NO}_{3}{ }^{-}$na solução do escoamento superficial em 2010 foram superiores ao limite máximo de $10,0 \mathrm{mg} / \mathrm{L}$ permitido pela legislação para os tratamentos AM, DLS100, DLS200 e CA100. Em 2012 as concentrações de $\mathrm{NO}_{3}{ }^{-}$estiveram abaixo do limite para todos os tratamentos avaliados.

5 - As concentrações de $\mathrm{P}$ disponível no escoamento superficial em 2010 ficaram abaixo do limite máximo de 0,1 mg/L permitido pela legislação para todos os tratamentos avaliados. Enquanto que em 2012 as concentrações desse elemento ficaram acima do limite para os tratamentos Controle, AM, DLS100 e DLS200. 6 - As concentrações de $\mathrm{Cu}$ e $\mathrm{Zn}$ no escoamento superficial em 2010 ficaram acima do limite máximo de 0,009 $\mathrm{mg} / \mathrm{L}$ e $0,18 \mathrm{mg} / \mathrm{L}$ respectivamente para todos os tratamentos estudados. Em 2012 as concentrações de $\mathrm{Cu}$ na enxurrada foram superiores ao limite para os tratamentos Controle, AM, DLS100 e DLS200, enquanto que para as concentrações de $\mathrm{Zn}$ os valores ficaram abaixo do limite permitido em todos os tratamentos.

7 - As concentrações de $\mathrm{NH}_{4}{ }^{+}, \mathrm{NO}_{3}{ }^{-}, \mathrm{P}_{\text {disp. }}, \mathrm{Zn}$ e $\mathrm{Cu}$ no escoamento superficial observadas neste estudo constituem uma fonte poluidora para águas superficiais de classe I, indicando que a aplicação de adubos orgânicos e mineral deve ser monitorada para não causar contaminação ambiental e riscos à saúde humana.

8 - A utilização da cama de frango como fertilizante do solo pode promover alterações nas propriedades físicas do solo que contribuem para o aumento da infiltração da água, refletindo em menor perda de água e solo e concentração de nutrientes no escoamento superficial. $\mathrm{O}$ uso deste adubo, no entanto, deve ser monitorado, uma vez que havendo enxurrada, as concentrações de nutrientes na água escoada podem exceder os limites máximos permitidos pela legis lação brasileira e tornarse uma fonte poluidora para águas superficiais .

9 - A aplicação de dejeto líquido suíno como fertilizante no solo pode elevar as perdas de água e solo e concentração de nutrientes no escoamento superficial ultrapassando os limites permitidos na legislação brasileira, podendo causar poluição das águas superficiais. Desta forma, seu uso deve ser constantemente monitorado a fim de diminuir os riscos ambientais.

\section{Agradecimentos}

Ao Instituto Agronônimo do Paraná - IAPAR, por permitir a instalação, operação e realização do experimento e também por ceder toda estrutura necessária para obtenção, análise e discussão dos dados.

\section{Referências}

Adeli, A., Sistani, K. R., Rowe, D. E., Tewolde, H. 2007. Effects of Broiler Litter Applied to No-Till and Tillage Cotton on Selected Soil Properties. Soil Science Society of American Journal 71, 974-983.

Aita, C., Port, O., Giacomini, S. J. 2008. Nitrato no Solo com Aplicação De Dejetos Líquidos De Suínos no Milho em Plantio Direto. Revista Brasileira de Ciência do Solo 32, 2101-2111.

Allen, B. L., Mallarino, A. P. 2008. Effect of Liquid Swine Manure Rate, Incorporation, and Timing of Rainfall on Phosphorus Loss with Surface Runoff. Journal of Environmental Quality 37, 125-137.

Alves, R. I S.; Tonani, K. A. A.; Nikaido, M.; Cardoso, O. O.; Trevilado, T. M. B.; SeguraMuñoz, S. I. 2010. Avaliação da concentração de metais pesados em águas superficiais e sedimentos do córrego Monte Alegre e afluente, Ribeirão Preto, SP, Brasil. Ambi-Água, 5, 122132.

Anami, M. H., Sampaio, S. C., Suszek, M., Gomes, S. D., Queiroz, M. M. F. 2008. Deslocamento miscível de nitrato e fosfato proveniente de água residuária da suinocultura em colunas de solo. Revista Brasileira de Engenharia Agrícola e Ambiental 2, 75-80.

ANDREOLA, F.; COSTA, L. M.; OLSZEVSKI, N. 2000. Influência da cobertura vegetal de inverno e da adubação orgânica e, ou, mineral sobre as propriedades físicas de uma Terra Roxa Estruturada. Revista Brasileira de Ciência do Solo, Viçosa, v.24, p.857-865.

Arruda, C. A. O. Alves, M. V., Mafra, A. L., Cassol, P. C., Albuquerque, J. A.; Santos, J. C. P. 2010. Aplicação de Dejeto Suíno e Estrutura de Um Latossolo Vermelho Sob Semeadura Direta. Ciência Agrotécnica 34, 804-809.

Atlas Ambiental da Cidade de Londrina. Disponível: http://www.uel.br/revistas/atlas ambiental/. Acesso: 22 jun. 2015.

Barbosa, G. M. C., Miyazawa, M. 2009. Dispersão da argila em água em solos argilosos em função da adição de esterco de animais. In.: SIGERA, 2009, Florianópolis - SC. Anais do I Simpósio Internacional sobre Gerenciamento de Resíduos de Animais. Florianópolis-SC.

Barbosa, G. M. C., Miyazawa, M., Ruiz, D. B. 2011. Avaliação da Aplicação de Dejetos de Animais na Infiltração da Água no Solo. In.: II REUNIÃ O 
PARANAENSE DE CIÊNCIA DO SOLO, 2011, Curitiba-PR. Anais da II Reunião Paranaense de Ciência do Solo. Curitiba-PR.

Basso, C. J. 2003. Perdas de Nitrogênio e Fósforo com Aplicação no Solo de Dejeto Líquido Suínos. Tese (Doutorado) Santa Maria, Universidade Federal de Santa Maria.

Basso, C. J., Ceretta, C. B., Durigon, R., Poletto, N., Girotto, E. 2005.Dejeto líquido de suínos: II perdas de nitrogênio e fósforo por percolação no solo sob plantio direto. Ciência Rural 35, 12341242.

Bennett, H. H. 1955. Elements of Soil Conservation. Mcgraw-Hill: New York.

Bertol, O. J., Rizzi, N. E., Bertol, I., Roloff, G. 2007. Perdas de solo e água e qualidade do escoamento superficial associadas a erosão entre sulcos em área cultivada sob semeadura direta e submetida as adubações mineral e orgânica. Revista Brasileira de Ciência do Solo 31, 781-792.

Bertol, O. J., Fey, E., Favaretto, N., Lavoranti, O. J., Rizzi, N. E. 2010. Mobilidade De P, Cu E Zn em Colunas de Solo sob Sistema de Semeadura Direta Submetido às Adubações Mineral e Orgânica. Revista Brasileira de Ciência do Solo, Viçosa 34, 1841-1850.

BERTOL, I; GOBBI, E.; BARBOSA, F. T.; PAZFERREIRO, J.; GEBLER, L.; RAMOS, J. C.; WERNER, R. S. 2011. Erosão hídrica em campo nativo sob diversos manejos: perdas de água e solo e de fósforo, potássio e amônio na água de enxurrada. Revista Brasileira de Ciência do Solo, Viçosa, v. 35, p.1421-1430.

Bertoni, J., Lombardi Neto, F. 2005. Conservação dos Solos. $5^{\mathrm{a}}$ ed. São Paulo: Ícone.

BRASIL. 2005. Resolução CONAMA nº.357. de 18 março.

Bundy, L.G., Andraski, T.W., Powell, J.M. 2001. Management practice effects on phosphorus losses in runoff in corn production systems. Journal of Environmental Quality 30, 18221828.

CABRAL, N. M. T. 2007.Teores de nitrato (NO3-) e amônio (NH4+) nas águas do aquífero barreiras nos bairros do reduto, nazaré e umarizal Belém/PA. Química Nova, vol. 30, n.8, p.18041808.

Caovilla, F. A., Sampaio, S. C., Pereira, J. O., Vilas Boas, M., Gomes, B. M., Figueirêdo, A. C. 2005. Lixiviação de Nutrientes Provenientes de Águas Residuárias em Colunas de Solo Cultivado com Soja. Revista Brasileira de Engenharia Agrícola e Ambiental 9, 283-287.

Carvalho, J. C. B., Orsine, J. V. C. 2011. Contaminação do Meio Ambiente por Fontes Diversas e os Agravos à Saúde da População. Enciclopédia Biosfera 7, 1107-1118.

Cassol, E. A., Lima, V. S. 2003. Erosão em entressulcos sob diferentes tipos de preparo e manejo do solo. Pesquisa Agropecuária Brasileira 38, 117-124.
Castro Filho, C., Costa, M. A. T., Caviglione, J. H. 2003. Potencial fertilizante e alterações físicas nos solos decorrentes da utilização de chorume suíno. In: XXIX CONGRESSO BRASILEIRO DE CIÊNCIA DO SOLO, 2003, Ribeirão PretoSP. Anais do XXIX Congresso Brasileiro de Ciência do Solo. Ribeirão Preto-SP.

Celik, I., Gunal, H., Budak, M., Akpinar, C. 2010. Effects of long-term organic and mineral fertilizers on bulk density and penetration resistance in semi-arid Mediterranean soil conditions. Geoderma 160, 236-243.

Ceretta, C. A., Basso, C. J., Vieira, F .C .B., Herbes, M. G., Moreira, I. C. L., Berwanger, A. L. 2005. Dejeto líquido de suínos: I- perdas de nitrogênio e fósforo na solução escoada na superfície do solo, sob plantio direto. Ciência Rural 35, 12961304.

Cogo, N. P., Levien, R., Schwarz, R. A. 2003. Perdas de solo e água por erosão hídrica influenciadas por métodos de preparo, classes de declividade e níveis de fertilidade do solo. Revista Brasileira de Ciência do Solo 27, 743-753.

Condé; M. S., Homem, B. G. C., Almeida Neto, O. B., Magno, A., Santiago, F. 2012. Influência da Aplicação de Águas Residuárias de Criatórios de Animais no Solo: Atributos Químicos e Físicos. Revista Brasileira de Agropecuária Sustentável 2, 99-106.

Condé; M. S., Almeida Neto, O. B., Homem, B. G. C., Ferreira, I. M., Silva, M. D., 2013. Impacto da fertirrigação com água residuária da suinocultura em um latossolo vermelho-amarelo. VÉRTICES 15, 161-178.

Costa, A. M., Ribeiro, B. T., Silva, A. A., Borges, E. N. 2008. Estabilidade de Agregados de um latossolo vermelho tratado com cama de peru. Ciência e Agrotecnologia, 32, 73-79.

Costa, A. M., Borges, E. N., Silva, A. A., Nolla, A., Guimarães, E. C. 2009. Potencial de Recuperação Física de um Latossolo Vermelho, Sob Pastagem Degradada, Influenciado pela Aplicação de Cama de Frango. Ciência e Agrotecnologia 33, 1991-1998.

Costa, V. L. 2008. Formas de fósforo e seu transporte pela enxurrada num latossolo que recebeu lodo de esgoto. Dissertação (Mestrado). Campinas. Instituto Agronômico - Curso de PósGraduação em Agricultura Tropical e Subtropical

Dal Bosco, T. C., Sampaio, S. C., Opazo, M. A. U., Gomes, S. D., Nóbrega, L. H. P. 2008. Aplicação de Água Residuária de Suinocultura em Solo Cultivado com Soja: Cobre e Zinco no Material Escoado e no Solo. Engenharia Agrícola 28, 699709.

Dieter, J. 2009. Poluição difusa por $\mathrm{P}$ devido à aplicação de água residuária da suinocultura sob condição de chuva simulada. Dissertação (Mestrado). Cascavel. Universidade Estadual do Oeste do Paraná 
Doblinski, A. F., Sampaio, S. C., Silva, V. R., Nóbrega, L. H. P., Gomes, S. D., Dal Bosco, T. C. 2010. Nonpoint source pollution by swine farming wastewater in bean crop. Revista Brasileira de Engenharia Agrícola e Ambiental 14, 87-93.

Dortzbach, D., Léis, C. M., Couto, R.R., Beber, C.L., Comin, J.J. 2008. Estabilidade de agregados do solo submetido a diferentes aplicações de dejetos suínos e ureia em um Argissolo. Florianópolis, EPAGRI, Disponível em: < http://intranetdoc.epagri.sc.gov.br/producao_tec nico_cientifica/DOC_3081.pdf>. Acesso: 16 de abril de 2015.

Erthal, V. J. T., Ferreira, P. A., Matos, A. T., Pereira, O. G. 2010. Alterações físicas e químicas de um Argissolo pela aplicação de água residuária de bovinocultura. Revista Brasileira de Engenharia Agrícola e Ambiental 14, 467-477.

Fey, R., Lana, M. C., Zoz, T., Rochart, A., Luchese, E. B. 2010. Relações entre lixiviação de nitrato e produção de biomassa do milho com dejetos suínos provenientes de diferentes tratamentos. Revista Brasileira de Ciências Agrárias. Recife 5, 212-218.

Fusco, J. C., Timofiecsyk, A., Favaretto, N., Pauletti, V., Dieckow, J. 2009. Perdas de Água e Solo sob Chuva Natural em Plantio Direto com Aplicação de Dejeto Líquido Bovino. Synergismus scyentifica 4.

Gabriel, M., Wastowski, A. D., Volpatto, F., Caetano, J. M., Zeni, C., Hedlund, F. S., Mendonça, A. M., Roppa, Alex. 2012. Níveis de Fósforo e Cobre em Águas de Consumo Humano e Animal em Propriedades Rurais Produtora de Suíno. In.: XXII Mostra de Iniciação Científica, 2012. Anais da XXII Mostra de Iniciação Científica, Passo Fundo-RS.

Gessel, P. D., Hansen, N. C., Moncrief, J. F., Schmitt, M. A. 2004. Rate of Fall-Applied Liquid Swine Manure: Effects on Runoff Transport of Sediment and Phosphorus. Journal of Environmental Quality 33, 1839-1844.

Giddens, J., Barnett, A. P. 1980. Soil Loss and Microbiological quality of runoff fron land treatedwith poultry litter. Journal of Environmental Quality 9.

Gilles, L., Cogo, N. P., Bissani, C. A., Bagatini, T., Portela, J. C. 2009. Perdas de água, solo, matéria orgânica e nutriente por erosão hídrica na cultura do milho implantada em área de campo nativo, influenciadas por métodos de preparo do solo e tipos de adubação. Revista Brasileira de Ciência do Solo 33, 1427-1440.

Girotto, E., Ceretta, C. A., Brunetto, G., Santos, D. R., Silva, L. S., Lourenzi, C. R., Lorensini, F., Costa, R., Vieira, B., Schmatz, R. 2010a. Acúmulo e Formas de Cobre e Zinco no Solo Após Aplicações Sucessivas de Dejeto Líquido de Suínos. Revista Brasileira de Ciência do Solo 34, 955-965.
Girotto, E., Ceretta, C. A., Santos, D. R., Brunetto, G., Andrade, J. G., Zalamena, J. 2010b. Formas de perdas de cobre e fósforo em água de escoamento superficial e percolação em solo sob aplicações sucessivas de dejeto líquido de suínos. Ciência Rural 40, 1948-1954.

Guadagnin, J. C. et. al. 2005. Perdas de solo, água e nitrogênio por erosão hídrica em diferentes sistemas de manejo. Revista Brasileira de Ciência do Solo 29, 277-286.

Guardini, R., Comin, J.J., Rheinheimer, D.S., Gatiboni, L.C., Tiecher, T., Schmitt, D.E., Bender, M.A., Filho, P.B., Oliveira, P.A.V., Brunetto, G. Phosphorus accumulation and pollution potential in a Hapludult fertilized with pig manure. Revista Brasileira de Ciência do Solo 36, 1333-1342.

Hentz, P., Carvalho, N. L. 2014. Impactos ambientais da fertilização orgânica em sistemas agropecuários na região sul-brasileira. Revista Eletrônica em Gestão, Educação e Tecnologia Ambiental 18, 340-352.

Homem, B. G. C., Almeida Neto, O. B., Condé, M. S., Silva, M. D., Ferreira, I. M. 2014. Efeito do uso prolongado de água residuária da suinocultura sobre as propriedades químicas e físicas de um Latossolo Vermelho-Amarelo. Científica 42, 299-309.

Hooda, P.S., Truesdale, V.W., Edwards, A.C., Withers, P.J.A., Aitkend, M.N., Miller, A., Rendell, A.R. 2001. Manuring and fertilization effects on phosphorus accumulation in soils and potential environmental implications. Advances in Environmental Research 5, 13-21.

Jadoski, S. O., Saito, L. R., Prado, C., Lopes, E. C., Sales, L. L. S. R. 2010. Características da lixiviação de nitrato em áreas de agricultura intensiva. Pesquisa Aplicada \& Agrotecnologia 3, 193-200.

KINGERY, W. L., WOOD, C. W., DELANEY, D. P., WILliANS, J. C., MULLINS, G. L. 1994. Impact of Long-Term Application of Broiler Litter on Environmentally Related Soil Properties. Journal of Environmental Quality 23, 139-147.

Kleinman, P. J. A., Sharpley, A. N., Moyer, B. G., Elwinger, G. F. 2002. Effect of Mineral and Manure Phosphorus Sources on Runoff Phosphorus. Journal of Environmental Quality 31, 2026-2033.

Konzen, E. A., Alvarenga, R. C. 2005. Manejo e utilização de dejetos animais: aspectos agronômicos e ambientais. Sete Lagoas: Embrapa-CNPMS, Circular técnica, 63.

Lemos, A. M. 2011. Matéria orgânica e perdas de solo, água e nutrientes por erosão em sistemas de preparo e de adubação orgânica e mineral em Argissolo vermelho amarelo. Dissertação (Mestrado). Porto Alegre. Universidade Federal do Rio Grande do Sul. 
Lima-E-Silva, P. P., Guerra, A. T., Mousinho, P., Bueno, C., Almeida, F, G, Malheiros, T. M. M., Souza Jr, A. B. 2002. Dicionário brasileiro de Ciências Ambientais. $2^{\text {a }}$ ed. Rio de Janeiro: Thex.

Lima, L. P. 2007. Avaliação física de um latossolo vermelho textura média, influenciada pela aplicação de dejetos de suínos e cama aviária. Dissertação (Mestrado). Uberlândia, Universidade Federal de Uberlândia.

Lourenzi, C.R., Ceretta, C.A., Girotto, E., Brunetto,G., Lorensini, F., Tiecher, T.L., Vieira, R.C.B. 2008. Transferência de Cobre e Zinco por Escoamento Superficial em Solo com Sucessivas Aplicações de Dejeto Líquido de Suínos. In: XXVIII Reunião Brasileira de Fertilidade do Solo e Nutrição de Plantas Fertibio, 2008, Londrina. Anais da XXVIII Reunião Brasileira de Fertilidade do Solo e Nutrição de Plantas Fertibio.

Lourenzi, C. R., Ceretta, C. A., Cerini, J. B., Ferreira, P. A. A., Lorensini, F., Girotto, E., Tiecher, T. L., Schapanski, D. E., Brunetto, G. 2014b. Available content, surface runoff and leaching of phosphorus forms in a typic hapludalf treated with organic and mineral nutrient sources. Revista Brasileira de Ciência do Solo 38, 949958.

Lunardi Neto, A., Albuquerque, J. A., Almeida, J. A., Mafra, A. L., Medeiros, J. C., Alberton, A. 2008. Atributos Físicos do Solo em Área de Mineração de Carvão Influenciados pela Correção da Acidez, Adubação Orgânica e Revegetação. Revista Brasileira de Ciência do Solo 32, 1379-1388.

Maack, R. 2002. Geografia Física do Estado do Paraná. Curitiba: Imprensa Oficial.

Mecabô Júnior, J. 2013. Influência de uma aplicação de dejeto líquido de suínos sobre atributos do solo e erosão hídrica em um nitossolo bruno. Dissertação (Mestrado). Lages. Universidade do Estado de Santa Catarina

Mori, H. F., Favaretto, N., Pauletti, V., Dieckow, J., Santos, W.L. 2009. Perda de água, solo e fósforo com aplicação de dejeto líquido bovino em latossolo sob plantio direto e com chuva simulada. Revista Brasileira de Ciência do Solo 33, 89-198.

Nyakatawa, E. Z., Reddy, K. C., Sistani, K. R. 2001. Tillage, cover cropping, and poultry litter effects on selected soil chemical properties. Soil Tillage Research 58, 69-79.

Novais, R. F., Alvarez, V. H., Barros, N. F., Fontes, R. L. F., Cantarutti, R. B., Neves, J. C. L. 2007. Fertilidade do solo. Viçosa - MG: Sociedade Brasileira de Ciência do Solo.

Obi, M. E., Ebo, P. O. 1995. The Effects of Organic and Inorganic Amendments on Soil Physical Properties and Maize Production in a Severely Degraded Sandy Soil in Southern Nigeria. Bioresource Technology 51, 117-123.
Oliveira, E., Parizotto, M. L. V. 1994. Características e uso fertilizantes do esterco de suínos. Londrina: IAPAR.

Pagliai, M., Bisdom, E. B. A., Ledin, S. 1983. Changes in Surface Structure (Crusting) After Application of Sewage Sludge and Pig Slurry to Cultivated Agricultural Soils in Northern Italy. Geoderma 30, 35-53.

Pelá, A. 2005. Efeito de Adubos Orgânicos Provenientes de Dejetos de Bovinos Confinados nos Atributos Físicos e Químicos do Solo e na Produtividade do Milho. Tese (Doutorado), Botucatu. Universidade Estadual Paulista.

Peles, D. 2007. Perdas de Solo, Água e Nutrientes sob Aplicação de Gesso e Dejeto Líquido de Suínos. Dissertação (Mestrado). Curitiba. Universidade Federal do Paraná

Pinto, F. A., Santos, F. L., Terra, F. D., Ribeiro, D. O., Sousa, R. R.J., Souza, E. D., Carneiro, M. A. C.; Paulino, H. B. 2012. Atributos de solo sob pastejo rotacionado em função da aplicação de cama de peru. Pesquisa Agropecuária Tropical 42, 254-262.

Resende, A. V. 2002. Agricultura e Qualidade da Água: contaminação da água por nitrato. Documentos 57. Planaltina: EMBRAPA Cerrados.

Resende, M., Curi, N., Rezende, S. B., Corrêa, G. F. 2007. Pedologia: base para distinção de ambientes. Lavras: Editora UFLA.

Roberts, R. J., Clanton, C. J. 2000. Surface Seal Hydraulic Conductivity As Affected By Livestock Manure Application. American Society of Agricultural Engineers. Transactions of the ASAE 43, 603-6013.

Seganfredo, M. A. 2000. A questão ambiental na utilização de dejetos de suínos como fertilizante do solo. Concórdia: Embrapa Suínos e Aves, Circular Técnica 22.

Shigaki, F., Sharpley, A. Prochnow, L. I. 2006. Source-Related Transport of Phosphorus in Surface Runoff. Journal of Environmental Quality 35, 2229-2235.

Silva, J.B., Bianchini, A., Weber, O.L.S., Scaramuzza, W.L.M.P., Silva, J.B., Maas, K.D.B. 2011. Atributos Físicos de um Latos solo Fertirrigado com Efluentes de Suínos. SIGERA. 2011, Foz do Iguaçu - PR. Anais do II Simpósio Internacional sobre Gerenciamento de Resíduos Agropecuários e Agroindustriais. Foz do Iguaçu $-\mathrm{PR}$.

Silveira, F. M., Favaretto, N., Dieckow, J., Pauletti, V., Vezzani, F. M., Silva, E. D. B. 2011. Dejeto Líquido Bovino em Plantio Direto: Perda de Carbono e Nitrogênio por Escoamento Superficial. Revista Brasileira de Ciência do Solo 5, 1759-1767.

Smanhotto, A., Sousa, A. P., Sampaio, S. S., Nóbrega, L. H. P., Prior, P. 2010. Cobre e zinco no material percolado e no solo com a aplicação de água residuária de suinocultura em solo 
cultivado com soja. Engenharia Agrícola 30, 346-357.

Smith, D. R., Owens, P. R.; Leytem, A. B.; Warnemunde, E. A. 2007. Nutrient losses from manure and fertilizer applications as impacted by time to first runoff event. Environmental Pollution 131-137.

Souza, R. F., Madeira, N. R., Figueiredo, C.C. 2014 Perdas de solo, água e nutrientes em área cultivada com hortaliças sob sistema de plantio direto.Revista Científic@1.

Tavares Filho, J. 2013. Física e conservação do solo e da água. Londrina: EDUEL.

Tejada, M., Gonzalez. J. L. 2008. Influence of two organic amendments on the soil physical properties, soil losses, sediments and runoff water quality. Geoderma 145, 325-334.

Tiecher, T., Brunetto, G., Ceretta, C.A., Comin, J.J., Girotto, E., Miotto, A., Moraes, M.P., Benedett, L., Ferreira, P.A.A., Lourenzi, C.R., Couto, R.R. 2013. Forms and accumulation of copper and zinc in a sandy typic Hapludalf soil after longterm application of pig slurry and deep litter.
Revista Brasileira de Ciência do Solo 37, 812824.

Timofiecsyk, A., Favaretto, N., Pauletti, V., Dieckow, J. 2012. Perdas De Carbono E Nitrogênio Com Aplicação De Dejeto Líquido Bovino Em Latossolo Muito Argiloso Sob Plantio Direto E Chuva Natural. Revista Brasileira de Ciência do Solo 36, 1924-1930.

Valim, W. C.; Panachuki, E. 2010. Perdas de solo e de água em argissolo cultivado com soja sob diferentes sistemas de manejo. In.: Encontro de Iniciação Científica. Anais do Encontro de Iniciação Científica, UEMS, n.2.

Veiga, M., Reinert, D. J., Reichert, J. M.; 2009. Aggregate stability as affected by short and longterm effects of tillage systems and nutrient sources of a Hapludox in Southern Brazil. Revista Brasileira de Ciência do Solo 33, 767777.

Weil, R. R., Kroontje, W. 1979. Physical Condition of a Clay Loam after Five years of Heavy poultry manure applications. Journal of Environmental Quality 08. 